\title{
The benzo[b]quinolizinium ion as a water-soluble platform for the fluorimetric detection of biologically relevant analytes
}

\author{
Anton Granzhan, ${ }^{\text {a,b }}$ Heiko Ihmels, ${ }^{* c}$ and Maoqun Tian ${ }^{d}$ \\ ${ }^{a}$ Institut Curie, PSL Research University, CNRS UMR9187, INSERM U1196, F-91405, Orsay, \\ France \\ ${ }^{b}$ Université Paris Sud, Université Paris-Saclay, CNRS UMR9187, INSERM U1196, F-91405 \\ Orsay, France \\ ${ }^{c}$ Department Chemie-Biologie, Organische Chemie II; and Center of Micro and Nanochemistry \\ and Engineering; Universität Siegen, Adolf-Reichwein-Str. 2, 57068 Siegen, Germany \\ ${ }^{d}$ The Scripps Research Institute, Department of Chemistry, 10550 North Torrey Pines Road, La \\ Jolla, California 92037, USA \\ E-mail:.ihmels@,chemie.uni-siegen.de
}

This paper is dedicated to Professor Harald Günther, University of Siegen, on the occasion of his 80th birthday

DOI: http://dx.doi.org/10.3998/ark.5550190.p009.339

\begin{abstract}
In this Account our efforts are described to establish the benzo[ $b]$ quinolizinium ion, also known as acridizinium or 4a-azoniaanthracene, as a water-soluble surrogate of anthracene for the development of selective fluorescent probes. It is demonstrated with selected examples that especially the 9-aminobenzo[b]quinolizinium is a donor-acceptor dye with favorable absorption and emission properties and may be used as a versatile building block for fluorescent light-up probes and ratiometric probes.
\end{abstract}

Keywords: Fluorescent probes, nitrogen heterocycles, quinolizinium, DNA stains, chemosensors, ion detection

\section{Table of Contents}

1. Introduction

2. Discussion

2.1 Synthesis

2.2 Reactivity

2.3 Photophysical properties 
2.4 The 9-aminobenzo[b]quinolizinium: a water-soluble donor-acceptor dye

2.5 DNA-sensitive fluorescent probes

2.6 Cation-sensitive fluorescent probes

2.7 Combination of cation- and DNA-sensitive emission properties in dual-mode chemosensors

2.8 Summary

3. Acknowledgements

4. Authors' Biographies

5. References

\section{Introduction}

The detection of analytes with fluorescent probes, also referred to as chemosensors, ${ }^{1}$ is a useful and versatile technique in chemistry and biology as well as in their neighboring disciplines, ${ }^{2-18}$ because it offers the advantages of fluorescence spectroscopy, e.g. high sensitivity and straightforward detection procedure, combined with the high potential of chemical synthesis to prepare a fluorophore with the required substitution pattern. Hence, numerous probe molecules have been developed for the fluorimetric detection of target analytes. ${ }^{2}$ The main principles of fluorescent sensing by organic chemosensors are well known and extensively described in recent reviews and monographs. ${ }^{2-18}$ In general, three different physical quantities may be determined from the emission of a molecule, namely emission energy, emission quantum yield and emission lifetime. $^{14,16}$ Therefore, essentially all fluorescent probes indicate a target analyte or a physical input (e.g. temperature, viscosity, pressure, $\mathrm{pH}$ ) by the change of at least one of these emission characteristics. As the steady-state emission spectra can be detected with simple and relatively cheap equipment, the majority of fluorescent probes transcribes the detection event on the molecular level into quenching or light-up effects or into significant shifts of the emission band. $^{16}$

Fluorescent chemosensors have to fulfill several requirements to be seriously considered for the detection of chemically or biologically relevant analytes. Firstly, the probe must be sufficiently selective, i.e. it should have the ability to discriminate unambiguously between the target analyte and other components in the analyzed medium. With respect to the detection signal, emission quenching should rather be avoided, because quenching may also be induced by other external factors, such as collision with heavy atoms or paramagnetic species, electron transfer, proton transfer and energy transfer, which cannot be excluded under real conditions. ${ }^{14,16,19}$ In contrast, light-up probes are preferred, whose emission intensity increases strongly upon interaction with the analyte, because this effect is usually characteristic of the particular analyte. Even more desirable are probes, whose emission energy changes in the presence of an analyte, ${ }^{20}$ because this effect allows the determination of the ratio between the relative fluorescence intensities at two different emission wavelengths that refer to the two 
different emitting entities (i.e. probe with or without bound analyte) at different wavelengths, thus enabling a quantification by a ratiometric analysis with "internal" calibration. Furthermore, probes that absorb and emit at the low-energy range of the visible light or even in the nearinfrared (NIR) region are especially useful for bioanalytical applications in order to minimize light-induced sample damage and to reduce autofluorescence of biological media. Last, but not least, good water-solubility or water-compatibility of the probes are a general requirements for any chemosensor that shall be applied in aqueous solutions. ${ }^{21}$

a)

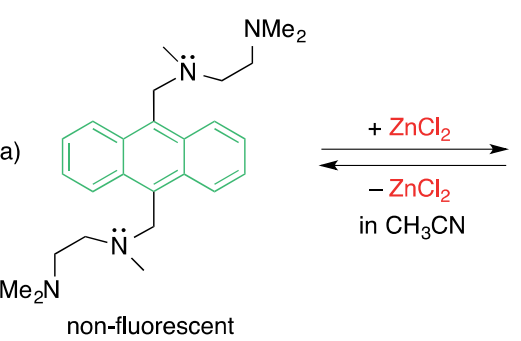

b)

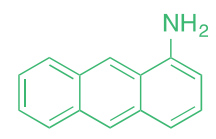

non-fluorescent

c)

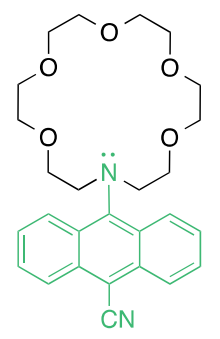

$\lambda_{\mathrm{fl}}=570 \mathrm{~nm}$

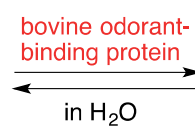

in $\mathrm{H}_{2} \mathrm{O}$

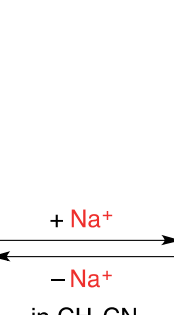

in $\mathrm{CH}_{3} \mathrm{CN}$
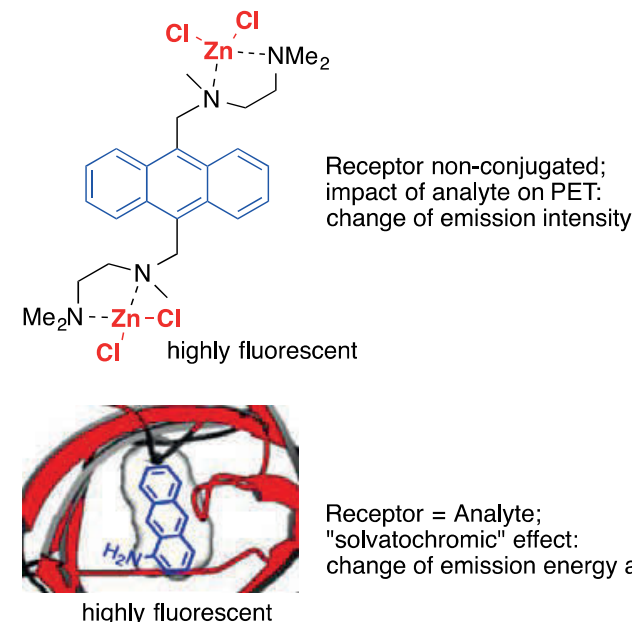

Receptor = Analyte;

"solvatochromic" effect:

change of emission energy and/or intensity

highly fluorescent

Conjugated receptor;

impact of analyte on ICT:

change of emission energy

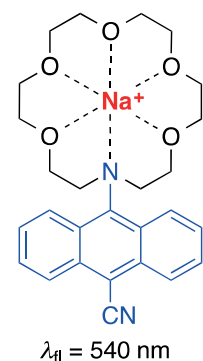

(a)

Scheme 1. Different modes of fluorescent signalling based on the anthracene fluorophore.

The anthracene fluorophore (1, Chart 1) is a useful and versatile building block for the construction of fluorescent probes and among the most often used polyaromatic hydrocarbons in this research field. ${ }^{22-25}$ In fact, anthracene has been used as building block for the design of different types of fluorescent probes with different modes of operation (Scheme 1). For example, the photoinduced electron transfer (PET) reaction of electron donor-substituted anthracene derivatives may be suppressed by an analyte (Scheme 1a). ${ }^{26} \mathrm{~A}$ similar light-up effect is accomplished with an aminoanthracene derivative that is non-fluorescent in water, but whose emission increases upon association in a protein binding site (Scheme $1 \mathrm{~b}$ ). ${ }^{27}$ In addition, the substituent effects in donor-acceptor-substituted anthracene derivatives may be affected by the analyte, leading to a change of the internal charge transfer (ICT) upon excitation and to a shift of the emission maximum (Scheme 1c). ${ }^{28}$ It is certainly beneficial for these studies that the 
synthesis of the long-known anthracene unit as well as the substituent effects on the photochemical and photophysical properties are well established and in most cases highly predictable. Unfortunately, anthracene and most of its derivatives are hardly soluble in water, which constitutes a major drawback for the application of this fluorophore in biologically or physiologically relevant media. Although the introduction of appropriate substituents may increase the solubility in aqueous media, ${ }^{29-34}$ the synthesis of such compounds is often tedious and time-consuming or the solubility-mediating functionalities interfere with the desired photophysical properties of anthracene. With this shortcoming in mind we turned our attention to the isoelectronic, but water-soluble benzo[b]quinolizinium (2a, Chart 1), ${ }^{35,36}$ that is also named 4a-azoniaanthracene or acridizinium, in which one bridgehead carbon atom of the anthracene scaffold is replaced with a quaternary nitrogen atom, yielding a permanent positive charge. Interestingly, despite the introduction of the heteroatom and the positive charge, the parent benzo[b]quinolizinium (2a) has photochemical and photophysical properties similar to anthracene. Therefore we started a project aiming at the development of functional dyes using the benzo[b]quinolizinium ion as a water-soluble surrogate of anthracene. In this Account our efforts along these lines are described. Specifically, it will be demonstrated that the benzo[b]quinolizinium ion is a useful building block for the design of anthracene-type watersoluble fluorescent probes.

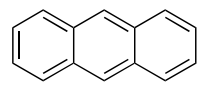

1

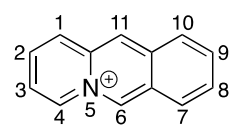

$2 a$

Chart 1. Structure of anthracene (1) and benzo[b]quinolizinium (2a).

It should be stressed that numerous other fluorescent dyes have been employed successfully for the development of chemosensors with remarkable properties. ${ }^{2-18}$ However, the overwhelming number of efficient and selective chemosensors, that have been explored and established during the past years, cannot be highlighted in this Account. With the intention to limit the extent of this Account to a reasonable size, a straight focus is kept on the class of benzo[ $b]$ quinolizinium ions.

\section{Discussion}

\subsection{Synthesis}

Several methods are available for the synthesis of benzo[b]quinolizinium derivatives. ${ }^{37-39}$ Probably the most efficient and the most frequently used synthetic approach is the cyclodehydration route as established by Bradsher et al. (Scheme 2, route 1). ${ }^{40}$ Hence, in the first reaction step the readily accessible benzyl bromide derivatives are made to react with a pyridine2-carbaldehyde. The latter is often protected as an oxime $(\mathrm{X}=\mathrm{HC}=\mathrm{NOH})^{41}$ or an acetal $[\mathrm{X}=$ $\left.\mathrm{HC}\left(-\mathrm{OCH}_{2} \mathrm{CH}_{2} \mathrm{O}-\right)\right]^{42}$ to improve the stability of the intermediate quarternary salts. The acid- 
catalyzed intramolecular hydroxymethylation reaction of the resulting $N$-benzylpyridinium derivative and subsequent dehydration result the benzo[b]quinolizinium in reasonable yields. This cyclodehydration method represents a widely applicable and efficient method that has been used for the synthesis of numerous derivatives. ${ }^{35,43,44}$ Nevertheless, in some cases the regioselectivity of the ring closure cannot be controlled or particular regioisomers are only available in very low yields, so that other approaches were proposed. For example, 10substituted benzo $[b]$ quinolizinium derivatives, that are not accessible by the cyclodehydration route, may be obtained from 2-(hydroxymethyl)phenyl-2-pyridyl methanol by in-situ formation of the corresponding chloride with phosphoryl chloride and subsequent cyclization (Scheme 2, route 2$).^{45,46}$
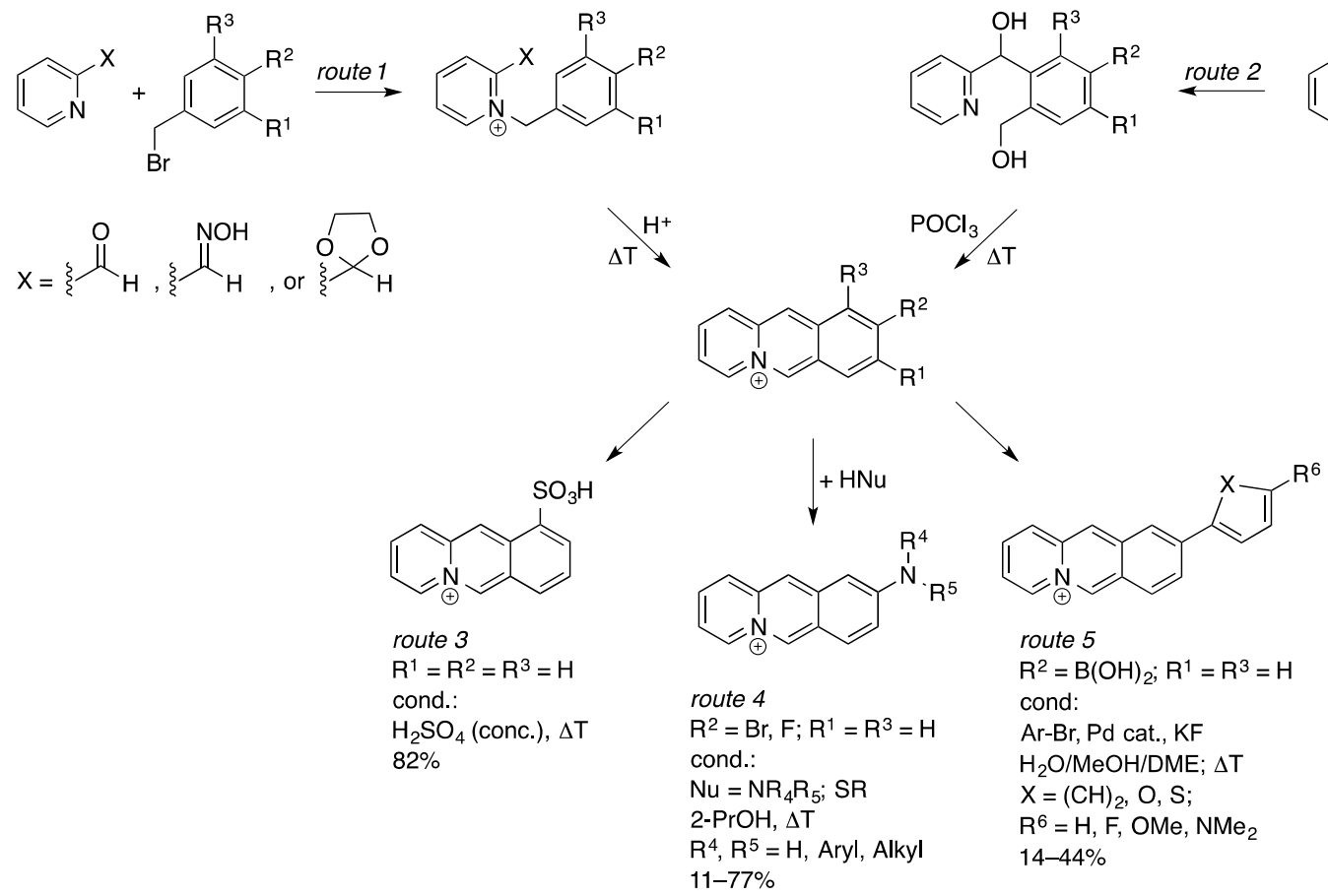

Scheme 2. Representative general synthetic routes to benzo[b]quinolizinium derivatives.

Some examples are known for an electrophilic aromatic substitution reaction at the benzo[b]quinolizinium core. ${ }^{47-49}$ The low regioselectivity of this reaction limits the applicability of this reaction for efficient derivatization; although this aspect was not explicitly discussed in the original literature. ${ }^{47-49}$ Complementarily, derivatives of the benzo[b]quinolizinium ion may be obtained by the nucleophilic aromatic substitution of halogen-substituted substrates; but these reactions also proceed only with moderate or even very low yields, ${ }^{50}$ presumably due to the competing ring-opening reaction. ${ }^{51}$ However, it was shown that arylamino substituents are introduced with this reaction in reasonable yields. In addition, metal-mediated coupling reactions may be performed with benzo[b]quinolizinium ions. For example, the boronic acid derivative is transformed to biaryl-type benzo[b]quinolizinium derivatives in a Suzuki-Miyaura coupling 
reaction. ${ }^{52}$ Although this approach was not fully explored with this particular class of compounds, so far, it was shown that resembling quinolizinium derivatives can be employed in other Pd-mediated coupling reactions such as the Stille or Sonogashira reaction. ${ }^{53-55}$

\subsection{Reactivity}

The chemistry of the quinolizinium ion and its derivatives has been reviewed several times. ${ }^{35,56-58}$ Along with the above mentioned electrophilic and nucleophilic aromatic substitution reactions, benzo[b]quinolizinium ions are readily reduced to the partially saturated derivatives. For example, treatment of the parent compound $\mathbf{2 a}$ with $\mathrm{NaBH}_{4}$ in $\mathrm{EtOH}$ results the 1,6,11,11atetrahydro-4H-benzo[b]quinolizinium as the main product, ${ }^{59}$ whereas Pd-catalyzed reduction with hydrogen gives the 6,11-tetrahydro-4H-benzo $[b]$ quinolizinium. ${ }^{60}$ Especially noteworthy is the reactivity of the benzo[b]quinolizinium ion towards strong nucleophiles and bases, in particular with the hydroxide anion (Scheme 3), as this is a relevant limitation of this system regarding the application in aqueous media at higher $\mathrm{pH}$. It was shown that nucleophiles add to the 6-position of the benzo[ $b$ ]quinolizinium, which leads to a ring opening reaction. ${ }^{43,61,62}$ In the case of the hydroxide anion this reaction gives - after tautomerism - the 2-(2picolyl)benzaldehyde derivative 3a. This product is fairly unstable and further decomposes; but the benzo $[b]$ quinolizinium (2a) may be regained by treatment of $\mathbf{3 a}$ with acid. ${ }^{43}$

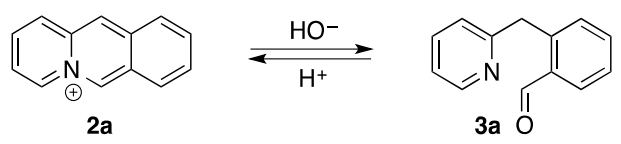

Scheme 3. Reversible base-induced ring-opening reaction of benzo[b]quinolizinium (2a).

Such as the photochromic anthracene derivatives ${ }^{63-67}$ the benzo[b]quinolizinium derivatives dimerize in a reversible [4+4] photocycloaddition in solution and in the solid state (Scheme 4). ${ }^{68}$ Initially, it was proposed that only one regioisomer anti-ht-4a is formed upon dimerization of the parent compound $\mathbf{2 a},{ }^{69}$ but a detailed reinvestigation of this reaction by Wolff et al. revealed that all of the four possible isomeric photodimers $\mathbf{4 a}$ are formed. ${ }^{70}$ The regioselectivity of the photodimerization is significantly improved by substitution effects as shown for the 9-aminobenzo[b]quinolizinium whose irradiation gives exclusively the head-to-tail dimers. $^{71}$ Highly regioselective photodimerization reactions of benzo[ $\left.b\right]$ quinolizinium derivatives were observed in the solid state. ${ }^{72-76}$ In all these cases the irradiation of the crystalline benzo[b]quinolizinium derivatives leads to the formation of the anti-head-to-tail dimers because of the highly ordered preorganization and restricted motion of the molecules in the solid state.

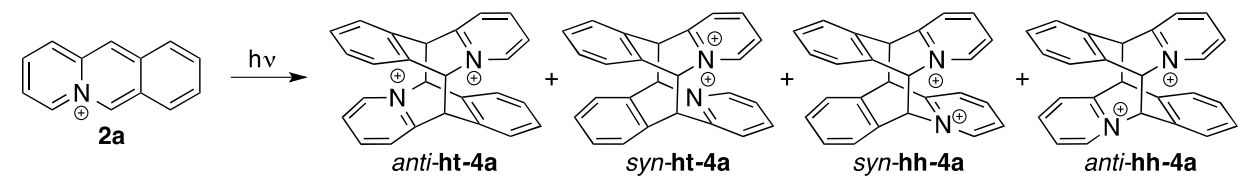

Scheme 4. Photodimerization of benzo[b]quinolizinium (2a). 


\subsection{Photophysical Properties}

The benzo $[b]$ quinolizinium ion (2a) as well as its annelated derivatives display pronounced absorption and emission properties that were investigated extensively and in detail, especially by the group of Bendig and Kreysig. ${ }^{77-81}$ In addition, a set of experimental ${ }^{82}$ and computational $^{83}$ absorption data of quinolizinium derivatives was compiled. As a general trend, the benzo[b]quinolizinium (2a) absorbs and emits essentially in the same range as anthracene (1) (Figure 1) with an absorption maximum at $396 \mathrm{~nm}$ and an emission maximum at $407 \mathrm{~nm}$ in methanol, respectively. ${ }^{77,80}$ The emission lifetime of the parent compound $2 \mathbf{a}$ is $4.4 \mathrm{~ns}$ in $\mathrm{CH}_{3} \mathrm{CN} .{ }^{80}$ These data indicate that the benzo[b]quinolizinium ion has the ability to substitute an anthracene fluorophore while essentially maintaining the photophysical properties. Furthermore, the quinolizinium structure offers a special advantage regarding the integration of the anthracene chromophore in an electron donor-acceptor system, that is required to accomplish pronounced dye-type properties. ${ }^{84}$ In anthracene, both donor and acceptor group have to be introduced as exocyclic substituents (auxochromes) to constitute a push-pull system. But apart from functionalization at the meso positions $(\mathrm{C} 9, \mathrm{C} 10)^{78,85}$ the synthesis of such anthracene derivatives, especially with donor and acceptor functionalities in the lateral positions, is a rather elaborate project. $^{86-90}$
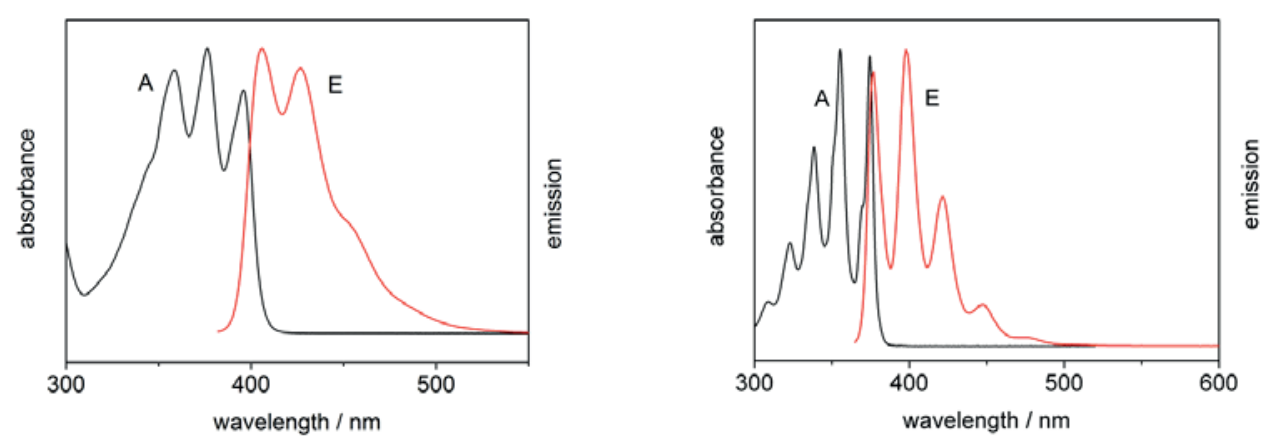

Figure 1. Absorption (A) and emission bands (E) of the parent benzo[b]quinolizinium (2a) in water (left) and of anthracene (1) in cyclohexane (right).

In contrast, the pyridinium unit within the benzo[b]quinolizinium already constitutes an intrinsic acceptor functionality, so that already the introduction of a single electron donating substituent in a "conjugated" position (i.e. position 2, 4, 6, 7, 9 or 11) establishes a donoracceptor system. Indeed, several donor-substituted benzo[b]quinolizinium derivatives are known; ${ }^{45,46,91}$ and along these lines we demonstrated that especially the amino-substituted derivatives closely resemble a rigidified hemicyanine-type dye. ${ }^{92,93}$ As a result of the amino-substitution these derivatives exhibit significantly red-shifted absorption with a pronounced chargetransfer band (Figure 2). ${ }^{94}$ Specifically, the comparison of the amino derivatives with the parent compound $\mathbf{2 a}$ or the bromo-substituted derivative $\mathbf{2 e}$ demonstrates the impact of the amino group on the characteristic dye properties of this class of compounds. In particular, the spectra reveal 
broad, pronounced red-shifted absorption bands that cause the yellow-orange to red color (Figure 3). DFT calculations have shown that the red-shifted long-wavelength bands correspond to ICT transitions that involve the transfer of electronic density from the exocyclic amino groups to the cationic hetarene upon excitation. ${ }^{92,93}$

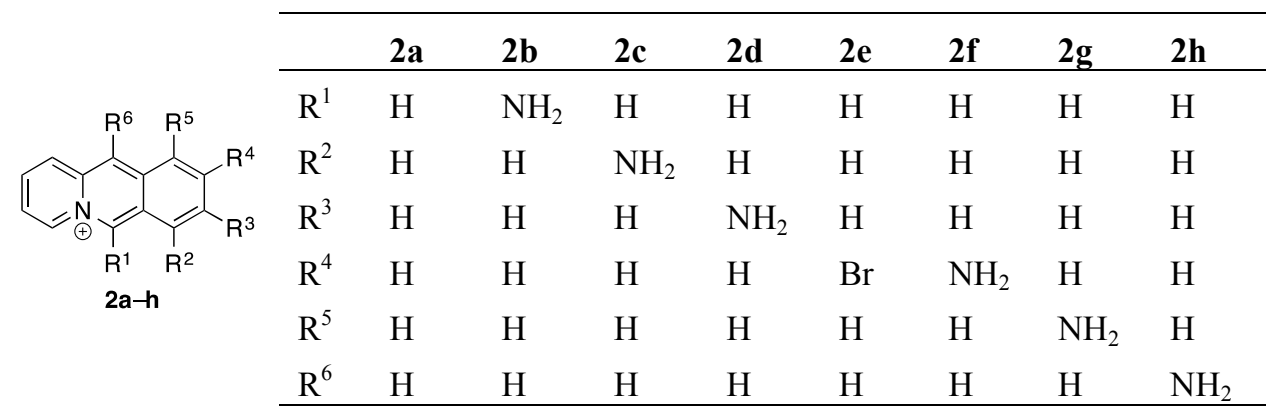

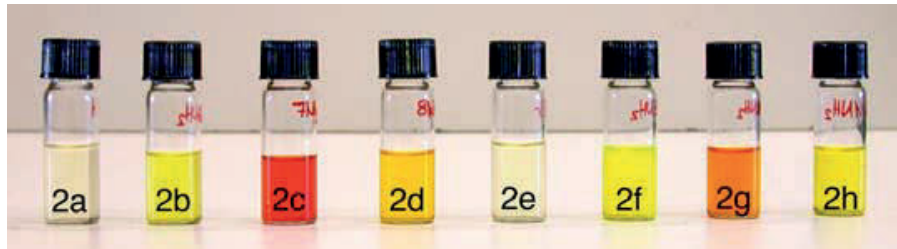

Figure 2. Colors of selected benzo[b]quinolizinium derivatives $\mathbf{2 a}-\mathbf{h}$ in $\mathrm{MeOH}(1.0 \mathrm{mM}){ }^{94}$

\subsection{The 9-aminobenzo[b]quinolizinium: A water-soluble donor-acceptor dye}

A survey of the known aminobenzo[b]quinolizinium derivatives revealed that the 9-aminosubstituted derivative $(\mathbf{2 f})^{92}$ exhibits favorable photophysical features that make this derivative an almost ideal starting platform for the development of water-soluble fluorescent probes (Figure 3).

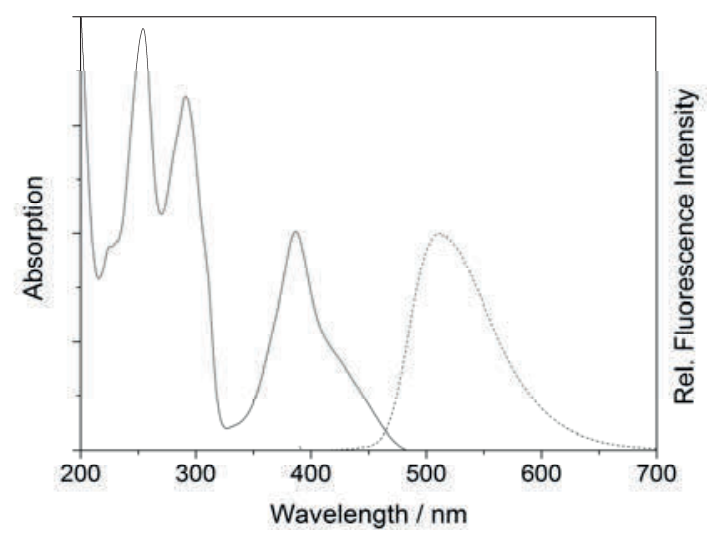

Figure 3. Absorption (solid line; $c=50 \mu \mathrm{M}$ ) and emission spectra (dashed line; $c=10 \mu \mathrm{M}, \lambda_{\mathrm{exc}}=$ $390 \mathrm{~nm}$ ) of 9-aminobenzo[b] quinolizinium (2f, as bromide salt) in $\mathrm{H}_{2} \mathrm{O}$.

In water solution, the compound has an absorption maximum at $\lambda_{\max }=385 \mathrm{~nm}$ with a redshifted 
shoulder corresponding to the CT band that tails off at ca. $480 \mathrm{~nm}$. This compound displays a bright green emission at $\lambda_{\max }=507 \mathrm{~nm}$ with a relatively high emission quantum yield of $\Phi_{\mathrm{fl}}=0.41\left(\mathrm{H}_{2} \mathrm{O}\right) .{ }^{95}$ Notably, the large Stokes shift of the fluorescence band ensures that there is only little interference between the excitation and emission light. With this useful dye in hand we went on to derivatize and functionalize it to make use of its absorption and emission properties in water-soluble chemosensors. Hence, we identified biologically relevant analytes that require the performance of analysis in aqueous media and we used the common design principles to selective fluorimetric detection of these target analytes. In the following, representative examples of the successful realization of this approach are presented and organized according to the class of analytes.

\subsection{DNA-sensitive fluorescent probes}

The comparison of the benzo[b]quinolizinium structure with the ones of known DNA binders, such as proflavine (5a), acridine orange (5b), methylene blue (6), or ethidium bromide (7), reveals some mutual structural features, that are characteristic elements of DNA intercalators. ${ }^{96-99}$ Firstly, all of these compounds have an essentially flat polycyclic aromatic system (marked red) that provides favorable $\pi$-stacking interactions with the DNA base pairs. Secondly, they carry a positive charge that is established by a quaternary nitrogen atom (marked blue) to gain favorable energy contributions from electrostatic interactions and from counter-ion release at the DNA backbone upon association of the ligand. In addition, cationic aromatic intercalators are often substituted with donor functionalities (marked green) that increase the affinity of the ligand towards DNA by additional hydrogen bonding (to minor extent) and by the introduction of a more pronounced donor-acceptor interplay, that increases the dipole-dipole interactions in the intercalation site. Based on this comparison between the benzo[b]quinolizinium (2a) and the intercalators 5-7 we inferred that derivatives of the former, especially the amino-substituted derivatives such as $\mathbf{2 f}$, should also exhibit significant DNA-intercalating properties. Thereupon, we established this class of ligands as versatile DNA binders, and we demonstrated over the years that annelated quinolizinium derivatives bind efficiently and selectively to duplex, triplex and quadruplex DNA as well as to DNA with abasic sites. ${ }^{100-106}$

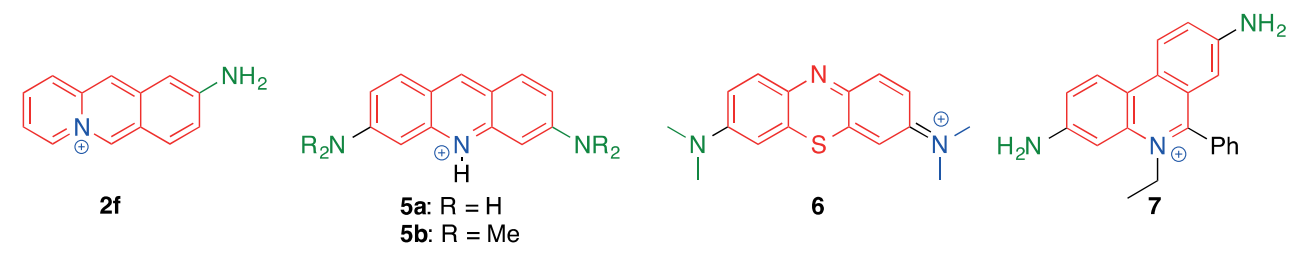

Chart 2. Comparison of 9-aminobenzo[b]quinolizinium (2f) with established DNA intercalators.

Considering the DNA-binding properties of benzo $[b]$ quinolizinium derivatives in concert with the favorable properties of the aminobenzo[b]quinolizinium fluorophore $\mathbf{2 f}$, we proposed that the latter compound should be a perfect chemosensor for the fluorimetric detection of nucleic acids. But unfortunately, on association with the DNA, the fluorescence of $2 \mathbf{f}$ is 
significantly quenched because of the PET reaction with the nucleic bases. ${ }^{107}$ This optical response to the DNA binding may be used for detection, but it mainly constitutes a major drawback, because other than emission enhancement the fluorescence quenching is also caused by other external factors and is therefore not very selective (see above). Hence, fluorescent probes are more desirable, whose emission intensity increases selectively in the presence of the analyte. However, such a light-up probe requires a chemosensor with a very low emission intensity in the absence of the analyte to prevent disturbing background fluorescence in the sample. Keeping these requirements in mind, we had to modify the structure of $\mathbf{2} \mathbf{f}$ such that it has a very low intrinsic fluorescence in homogeneous solution which increases upon complex formation with DNA. For that purpose, we chose the 2- $N$-arylamino-6-naphthalenesulfonates as a paradigm, whose emission is quenched by torsional relaxation of the $N$-aryl functionality in the excited state. $^{108}$ Thus, we synthesized a series of $9-N$-arylaminobenzo[ $\left.b\right]$ quinolizinium derivatives $\mathbf{8 a}-\mathbf{g}$ (Scheme 2, route 4) that display a very low fluorescence quantum yield (Scheme 5). ${ }^{95}$ We clearly demonstrated in detailed photophysical studies that the low intrinsic fluorescence quantum yield originates from conformational changes in the excited state, namely torsional relaxation by rotation about the $\mathrm{N}-\mathrm{C}_{\text {phenyl }}$ bond, as confirmed by the theoretically predicted dependence of the fluorescence quantum yield on the solvent viscosity. ${ }^{95,109,110}$ The derivatives were shown to intercalate into DNA with binding constants in the range of $10^{4}-10^{5} \mathrm{M}^{-1}{ }^{95}$ Most notably, the association of these ligands with DNA suppresses the conformational relaxation in the excited state due to the steric constraints in the intercalation site, which - except for the donor substituted cases (see discussion below) - results in an increase of the fluorescence intensity by a factor of up to 50 (Scheme 5), which is slightly larger than the enhancement of the emission intensity of the commonly employed DNA stains ethidium bromide (7) (factor 10) and Hoechst 33258 (factor 30) under identical conditions. ${ }^{111}$
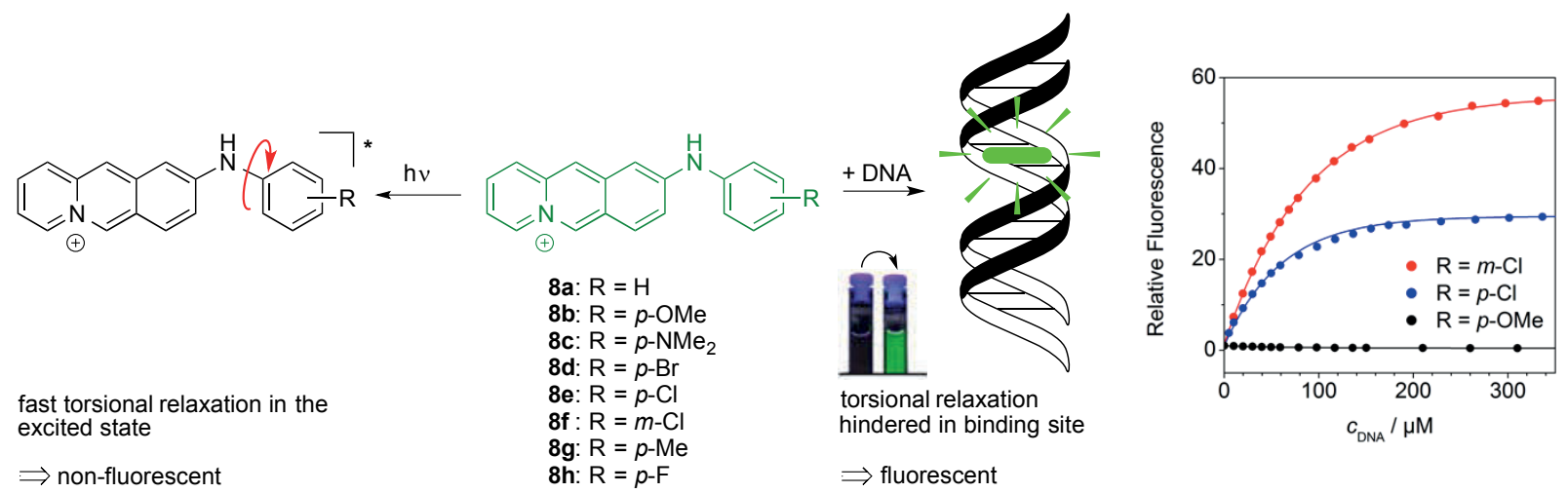

Scheme 5. Fluorescence light-up effect of 9-arylaminobenzo[b]quinolizinium derivatives upon association with DNA.

In a follow-up project, we varied the above described design of a DNA-sensitive fluorescent light-up probe. ${ }^{12}$ In the biaryl-type derivative $9 \mathbf{a}$ a torsional relaxation also operates in the 
excited state; but in this case a donor-substituted aryl ring is directly conjugated with the $\pi$ system of the quinolizinium, such that a photoinduced charge shift (CS) from the para-amino functionality to the benzo[b]quinolizinium may take place upon excitation. As a result, in the aminophenyl-substituted benzo[b]quinolizinium derivative 9a the excited state is affected by torsional relaxation, that determines the emission intensity, and by the extent of the photoinduced $\mathrm{CS}$, that determines the emission wavelength. These two processes are not independent, because the CS only operates from particular excited-state conformations, which is a typical feature of donor-acceptor-substituted fluorophores. ${ }^{113}$ Indeed, the benzo[b]quinolizinium 9a exhibits a low fluorescence quantum yield in aqueous solution $\left(\Phi_{\mathrm{fl}}=1.0 \times 10^{-3}\right.$ in phosphate buffer), which increases significantly with a maximum at $\lambda_{\mathrm{fl}}=699 \mathrm{~nm}$ in viscous media, e.g. glycerol $\left(\Phi_{\mathrm{fl}}=\right.$ $0.11)$, or upon association with calf thymus (ct) DNA $\left(\Phi_{\mathrm{fl}}=4.0 \times 10^{-2}\right)$, because in both cases the torsional relaxation in the excited state is significantly retarded. These results indicate that in homogeneous solution the rapid rotation about the biaryl axis leads to the unhindered formation of excited conformers that are involved in radiationless deactivation. In contrast, the hindrance or deceleration of free rotation in viscous solvents or within the binding pocket of a host molecule obviously interferes with the formation of the non-emissive conformer, thus leading to a light-up effect (Scheme 6). In addition, the protonation of 9a leads also to an enhancement of the emission intensity by a factor of 130, however, with a significant blue shift of the emission maximum, that resembles that of the parent 9-phenylbenzo[b]quinolizinium. ${ }^{52}$ The observation that the protonation of the amino functionality causes an increase of the emission intensity of 9a even without suppression of rotational freedom, along with the fact that the 9-phenylbenzo $[b]$ quinolizinium is highly fluorescent $\left(\Phi_{\mathrm{fl}}=0.31\right)$, led us to the interpretation, that the torsional relaxation of the biaryl unit induces the deactivation of the excited 9a only when it is accompanied by the formation of conformers that enable a CS from the electron-donating aminophenyl fragmen enables the fluorimetric detection $t$ to the benzo[ $b]$ quinolizinium.
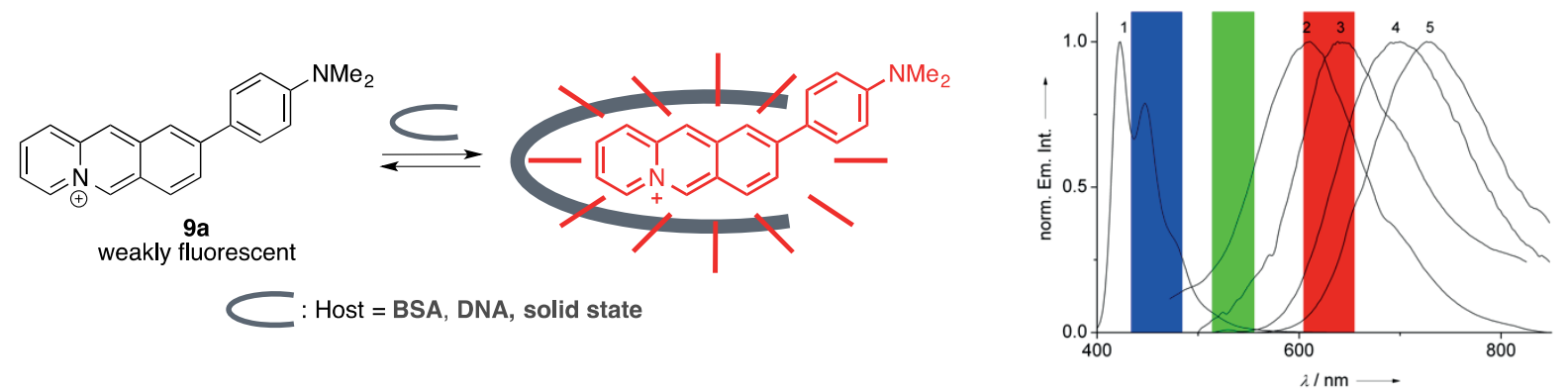

Scheme 6. Fluorescence light-up effect of 9-(4-dimethylaminophenyl)benzo[ $b]$ quinolizinium (9a) in aqueous solution at $\mathrm{pH} 1.7$ (1), or in the presence of bovine serum albumin (2), quadruplex DNA 22AG (4), double-stranded ct DNA (5), and in the solid state (3); $1: \lambda_{e x}=381 \mathrm{~nm} ; 2,4$ : $\lambda_{e x}=421 \mathrm{~nm} ; 3,5: \lambda_{e x}=450 \mathrm{~nm}$; overlay: range of the filters used in a confocal fluorescence microscope for cell experiments. Reproduced from Ref. 112. Copyright 2013 Wiley-VCH Verlag GmbH \& Co. 
Interestingly, the emission wavelength and the emission intensity of 9a depend on the type of host system and on the binding site (Scheme 6$)$. In the case of the double-stranded ct DNA $\left(K_{b}=\right.$ $\left.1.3 \times 10^{4} \mathrm{M}^{-1}\right)$, the fluorescence intensity increases with a maximum at $728 \mathrm{~nm}$ by a factor of 38 , whereas titration with quadruplex DNA $\left(K_{b}=8.3 \times 10^{4} \mathrm{M}^{-1}\right)$ led to an emission maximum at $697 \mathrm{~nm}$ with a light-up factor of 96 . We even observed an optical response of this chemosensor on association with a protein. Namely, the addition of bovine serum albumin (BSA) to 9a results in an increased fluorescence band with a maximum at $\lambda_{\mathrm{fl}}=609 \mathrm{~nm}$. The changes of the emission properties in different host systems are probably due to different binding modes of the ligand in the corresponding binding sites, which differ in size and most likely in polarity.

As the emission colors of 9a fall in the range of commonly employed detection filters of a confocal microscope, we were even able to use this chemosensor for the multicolor analysis of HeLa cells (Figure 4). With the blue filter $(435-485 \mathrm{~nm})$, the emission from small circular objects was observed that most likely originates from the protonated dye molecules in the acidic medium of the lysosomes. With a red filter $(605-655 \mathrm{~nm})$ the DNA-bound dye molecules in the nuclei were detected, along with the red emission in the cytoplasm due to interactions of 9a with RNA or proteins. The emission which is seen with the green filter $(515-555 \mathrm{~nm})$ may be caused by association of the dye with proteins in the cytoplasm.
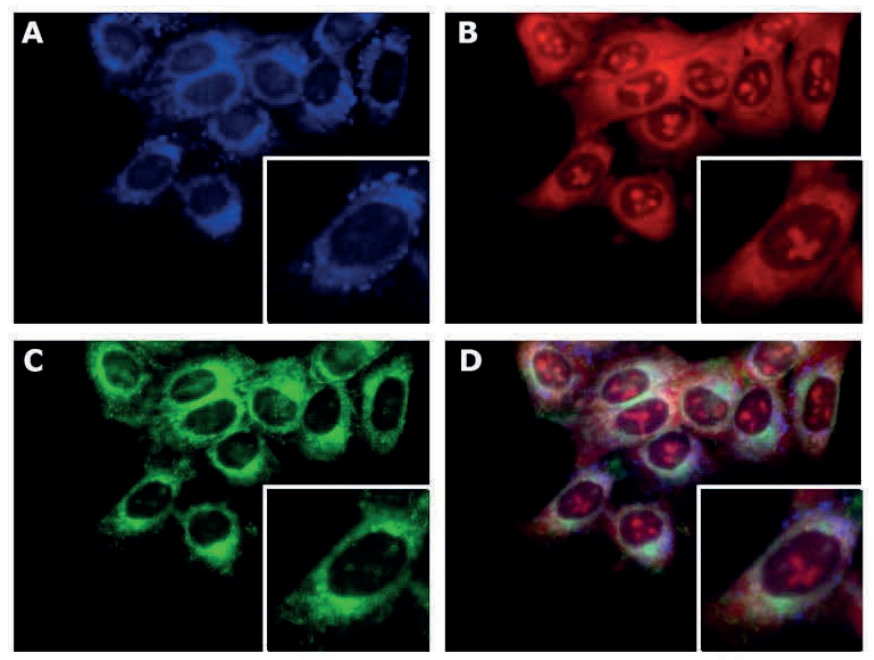

Figure 4. Fluorescence microscopic analysis of HeLa cells after incubation with 9a $(2.5 \mu \mathrm{M})$ for $1 \mathrm{~h}$. The different emission colors were separated by blocking filters. The inset in the panels represent an enlargement of one cell. Panel A: $\lambda_{f l}=435-485 \mathrm{~nm}$; Panel B: $\lambda_{f l}=605-655 \mathrm{~nm}$; Panel C: $\lambda_{f l}=515-555 \mathrm{~nm}$; panel D overlay of all pictures. Reproduced from Ref. 112. Copyright 2013 Wiley-VCH Verlag GmbH \& Co.

\subsection{Cation-sensitive fluorescent probes}

The 9-aminobenzo[ $b]$ quinolizinium fluorophore represents a typical donor-acceptor dye whose photophysical properties, especially the shift of the absorption and emission maxima, depend on 
the extent of the donor-acceptor interplay. ${ }^{92}$ As a consequence, an analyte that increases or decreases the electron-donating ability of the amino group will lead to hypsochromic or bathochromic effects, respectively, that in turn indicate the presence of the analyte (Scheme 1c). Such a change of the emission energy in the presence of an analyte has some practical advantages, because it allows a ratiometric detection of analytes (see Introduction). Based on these considerations, we proposed that the integration of the amino-functionality of $\mathbf{2} \mathbf{f}$ into an appropriate cation-responsive receptor unit enables the fluorimetric detection of biologically or environmentally relevant cationic analytes, ${ }^{114-118}$ as long as the amino group is directly involved in the complexation of the analyte.

We realized this concept with the derivative 10, ${ }^{119}$ because the bis(picolylmethyl)amino (bpa) receptor unit binds metal ions even in aqueous medium, and it has been employed already as receptor unit in $\mathrm{Zn}^{2+}$ or $\mathrm{Cd}^{2+}$-sensitive fluorescent probes. ${ }^{120}$ The target compound was synthesized by nucleophilic aromatic substitution reaction of the 9-fluorobenzo[ $b]$ quinolizinium with the corresponding amine (Scheme 2, route 4). Because the electron-withdrawing benzo $[b]$ quinolizinium ion decreases the electron density at the amino nitrogen atom of the bis(picolylmethyl)amino group, the derivative $\mathbf{1 0}$ shows a very good selectivity towards $\mathrm{Cu}^{2+}$ ions $\left(K_{\mathrm{b}}=4 \times 10^{4} \mathrm{M}^{-1}\right)$ and a weaker affinity to other transition metals, which is in agreement with the Irving-Wiliams series. ${ }^{121}$ The derivative $\mathbf{1 0}$ has a relatively strong fluorescence $\left(\Phi_{\mathrm{f} 1}=\right.$ 0.72 in water), that was significantly quenched upon titration of $\mathrm{Cu}^{2+}$ salts, however, with no shift of the emission maximum (Scheme 7).

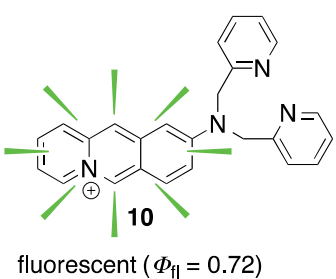

fluorescent $\left(\Phi_{f \mid}=0.72\right)$
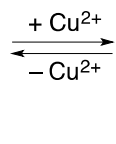

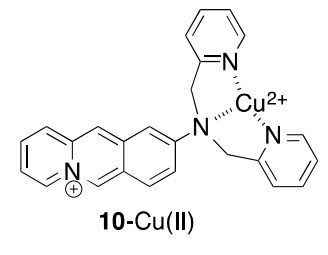

fluorescence quenched

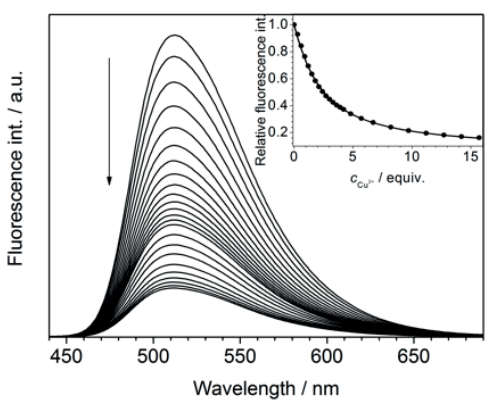

Scheme 7. Fluorescence quenching of the 9-[bis(picolylmethyl)amino]benzo[ $b]$ quinolizinium on addition of $\mathrm{Cu}^{2+}$. Conditions: $c_{10}=10 \mu \mathrm{M}$ in HEPES buffer, $\mathrm{pH} 7.3 ; \lambda_{\mathrm{ex}}=384 \mathrm{~nm}$; the arrows indicate the changes of absorption upon addition of $\mathrm{Cu}^{2+}$. Reproduced from Ref. 119 with permission from the Royal Society of Chemistry.

This development of the emission intensity of compound $\mathbf{1 0}$ upon complexation of $\mathrm{Cu}^{2+}$ ions enables the quantitative detection of the latter in water solution, which constitutes an advantage as compared with $\mathrm{Cu}^{2+}$-sensitive probes that are not soluble in water. ${ }^{122-127}$ The detection limit of this probe is $0.2 \mu \mathrm{M}$, and we have shown that the fluorimetric detection of $\mathrm{Cu}^{2+}$ by $\mathbf{1 0}$ is not disturbed by potentially competing or interfering cations such as $\mathrm{Co}^{2+}, \mathrm{Cd}^{2+}, \mathrm{Pb}^{2+}, \mathrm{Hg}^{2+}, \mathrm{Ag}^{2+}$, $\mathrm{Zn}^{2+}, \mathrm{Ni}^{2+}, \mathrm{Na}^{+}, \mathrm{K}^{+}, \mathrm{Mg}^{2+}, \mathrm{Ca}^{2+}$, not even when these ions are present in large excess (100 molar 
equiv.). Although these features may appear promising for fluorimetric detection of $\mathrm{Cu}^{2+}$ ion with chemosensor 10, this probe is far from being ideal, because it does not exhibit the anticipated shift of the emission maximum on metal-ion binding. As a consequence the detection output is just emission quenching that we do not consider an appropriate tool for fluorescent sensing of metal cations. It should be noted, however, that fluorescence quenching of fluorobenzo $[b]$ quinolizinium derivatives by halide ions was proposed as useful tool for the fluorimetric detection of bromide or iodide ions. ${ }^{128}$

To overcome the above mentioned shortcomings of probe $\mathbf{1 0}$ we turned our attention to crown-ether functionalities as receptor units, because it has been demonstrated already with numerous examples that the direct attachment of azacrown ether units to a fluorophore is a general design principle for the development of donor-acceptor based fluorescent probes that change emission wavelength upon complexation of a metal ion (Scheme 1c)..$^{3-12,122-127}$ Nevertheless, most crown ether host molecules do not bind the analyte to significant extent in water, ${ }^{129}$ so that the majority of probes can only operate in non-competitive organic solvents. Therefore, we focused our studies on the 1,4-dioxa-7,13-dithia-10-azacyclopentadecane receptor unit, that is known to bind $\mathrm{Hg}^{2+}$ ions in water with high affinity. Specifically, we synthesized the derivative $\mathbf{1 1}$ in which the 9-aminobenzo[b]quinolizinium is integrated into the azadithiacrown ether receptor (Scheme 8). ${ }^{130}$ We showed by spectrometric titrations that this host molecule complexes $\mathrm{Hg}^{2+}$ ions in water with an association constant $K_{\mathrm{b}}=1.5 \times 10^{4} \mathrm{M}^{-1}$. This complex formation between 11 and $\mathrm{Hg}^{2+}$ affects the donor properties of the amino functionality and thereby the donor-acceptor interplay within the fluorophore. As a result the emission intensity of 11 decreases and a significant blue-shift of the emission maximum from $523 \mathrm{~nm}$ to $500 \mathrm{~nm}$ developed that can be seen even by the naked eye as a change of the emission color from light green to blue. The result of the fluorimetric titration can be plotted as a ratiometric calibration curve, $I_{466} / I_{523}$ versus $\mathrm{Hg}^{2+}$ concentration (Figure 5). Moreover, it was demonstrated that the ratiometric detection of $\mathrm{Hg}^{2+}$ with the fluorescent probe $\mathbf{1 1}$ is possible even in the presence of the potentially interfering metal cations $\mathrm{Cd}^{2+}, \mathrm{Zn}^{2+}, \mathrm{Ni}^{2+}, \mathrm{Cr}^{3+}, \mathrm{Ca}^{2+}, \mathrm{Cu}^{2+}, \mathrm{Pb}^{2+}, \mathrm{Co}^{2+}$, and $\mathrm{Fe}^{3+}$. Only $\mathrm{Ag}^{+}$ions interfere with the fluorimetric mercury detection, as the former also induce a light-up effect and a blueshift of the emission maximum; however, to lesser extend as compared with $\mathrm{Hg}^{2+}$. Moreover, we demonstrated that $\mathrm{Hg}^{2+}$ and $\mathrm{Ag}^{+}$can be discriminated by complementary photometric analysis with the probe $8 \mathbf{i}$ (see below) as only in the presence of $\mathrm{Hg}^{2+}$ a deep red color develops. ${ }^{131}$ In summary, compound $\mathbf{1 1}$ was among the first examples of fluorescent probes that enable the selective ratiometric detection of $\mathrm{Hg}^{2+}$ in water and it nicely demonstrated the aptitude of the aminobenzo[b]quinolizinium fluorophore for the construction of effective fluorescent probes. 


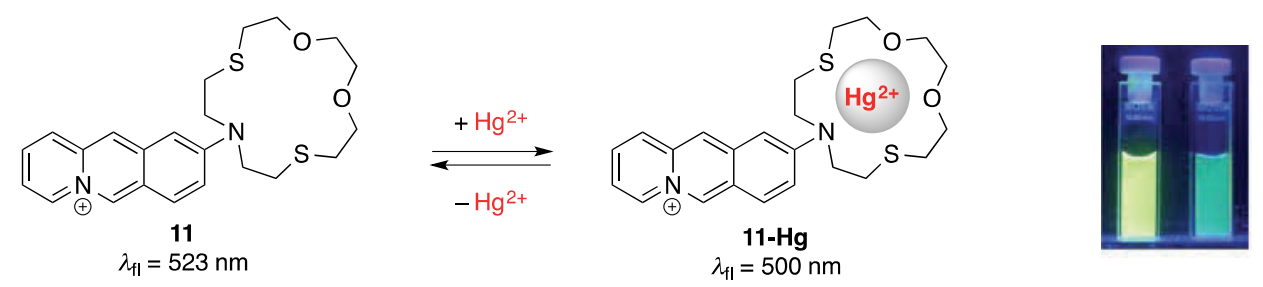

Scheme 8. Color change upon complexation of $\mathrm{Hg}^{2+}$ by the crown ether-benzo[b]quinolizinium conjugate 11 (right cuvette: 11; left cuvette: 11-Hg; $c_{11}=10 \mu \mathrm{M}$ ).

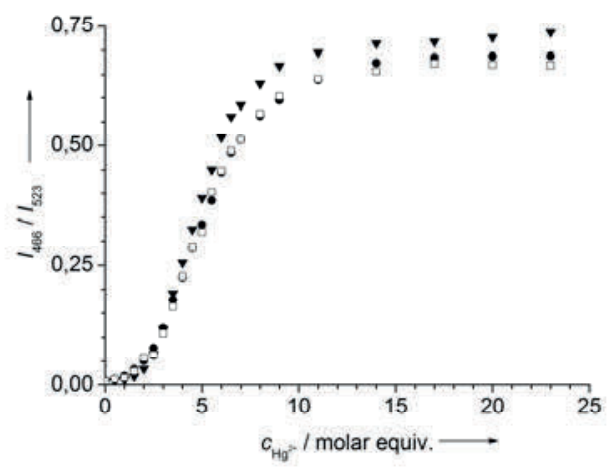

Figure 5. Ratiometric analysis of the fluorimetric titration of $\mathrm{Hg}^{2+}$ to $\mathbf{1 1}(c=10 \mu \mathrm{M})$ in the absence of other cations ( $\mathbf{\square}$, and in the presence of a the mixture of $\mathrm{Cd}^{2+}, \mathrm{Zn}^{2+}, \mathrm{Ni}^{2+}, \mathrm{Cr}^{3+}, \mathrm{Ca}^{2+}$, $\mathrm{Cu}^{2+}, \mathrm{Pb}^{2+}, \mathrm{Co}^{2+}$ and $\mathrm{Fe}^{3+}$ ( $\mathrm{O}, 1.0$ molar equiv.) or $\mathrm{Na}^{+}, \mathrm{Mg}^{2+}, \mathrm{Ca}^{2+}(\boldsymbol{\nabla}, 50 \mathrm{mM})$. Reproduced from Ref. 130 with permission from the Royal Society of Chemistry.

As we have shown with the derivative 9a that the donor-acceptor interplay remains intact if the amino group is exchanged with a donor-substituted phenyl ring, we extended our studies to the benzo[b]quinolizinium crown-ether conjugate $\mathbf{9 b} .^{132}$ This biaryl derivative is available by Suzuki-Miyaura coupling reaction (Scheme 1, route 5) and features a $\mathrm{Mg}^{2+}$-selective crown-ether unit that also serves as the electron donor. Such as the aminophenyl-substituted derivative 9a it shows a very low fluorescence quantum yield in water, alcohols or acetonitrile $\left(\Phi_{\mathrm{fl}}<0.01\right)$, most likely based on the same deactivation mechanism (see discussion above). Photometric titrations with $\mathrm{Mg}^{2+}$ in $\mathrm{MeCN}$ revealed a complexation of the metal cation to the crown ether with a binding constant $K_{b}=1.4 \times 10^{5} \mathrm{M}^{-1}$. This complex formation leads to the formation a very intense fluorescence band with a maximum at $495 \mathrm{~nm}$ and a light-up factor of 450 . In contrast, the addition of other cations such as $\mathrm{NH}_{4}^{+}, \mathrm{Na}^{+}, \mathrm{K}^{+}$to $\mathbf{9 b}$ did not induce this emission enhancement. Only the complexation of $\mathrm{Li}^{+}, \mathrm{Ba}^{2+}$, and $\mathrm{Ca}^{2+}$ resulted a relatively small increase of the fluorescence intensity by a factor of 8,10 , and 40 . Unfortunately, this chemosensor only operates properly in acetonitrile solution, because the complex between $\mathrm{Mg}^{2+}$ and the crown ether is too weak in water or in alcoholic solution. 

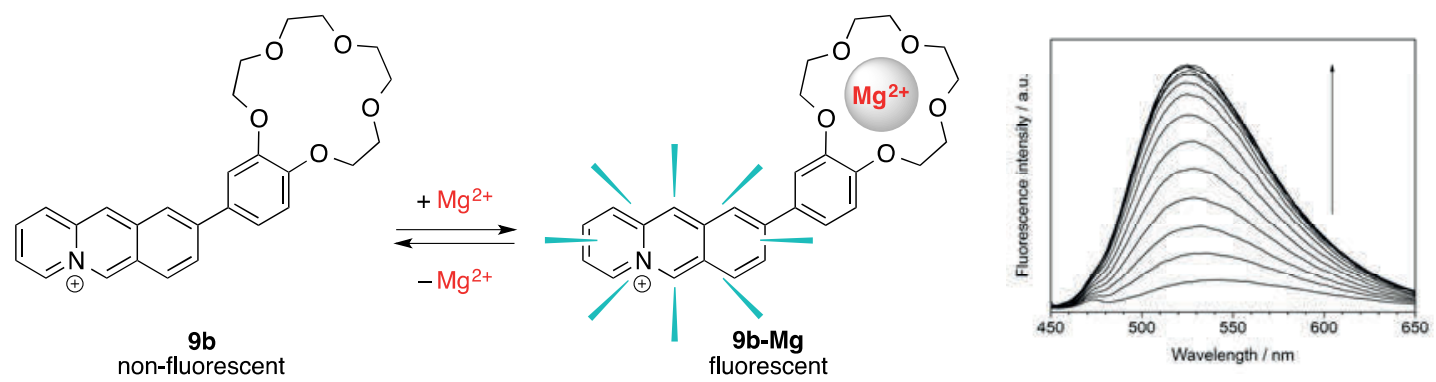

Scheme 9. Fluorescence enhancement upon complexation of $\mathrm{Mg}^{2+}$ by the crown etherbenzo[b]quinolizinium conjugate 9b. Conditions: $c_{9 \boldsymbol{b}}=10 \mu \mathrm{M}$ in $\mathrm{MeCN}, \lambda_{\mathrm{ex}}=395 \mathrm{~nm}$. The arrow indicates the changes of emission upon addition of $\mathrm{Mg}^{2+}$. Reproduced from Ref. 132 with permission from the Royal Society of Chemistry.

\subsection{Combination of cation- and DNA-sensitive emission properties in dual-mode chemosensors}

Based on the above-mentioned general principles or variations thereof, selective and efficient fluorescent chemosensors have been developed for numerous relevant analytes. ${ }^{2-18}$ It should be stressed, however, that most reported examples, such as the ones stated above, employ the rather conventional approach that one probe can be used only for one particular analyte. But in real samples several different analytes have to be detected at the same time. Obviously, the simplest approach for the required multi-analyte sensing is the consecutive - or ideally simultaneous application of different highly selective chemosensors, each of which is specific for one of the analytes. In fact, based on this principle, commercial sensor devices have already been presented that enable the fluorimetric detection of $\mathrm{Na}^{+}, \mathrm{K}^{+}$and $\mathrm{Ca}^{2+} .133$

A more elegant and efficient concept involves just one multifunctional chemosensor that is able to detect different analytes or analyte combinations with distinctly separate output signals, as shown in a simplifying cartoon in Scheme 10 (approach $A$ ). Thus, in the most simple case of multi-analyte detection, an ideal receptor-based chemosensor for the detection of two independent analytes consists of one fluorophore unit that is attached to two different receptor units. The latter should selectively bind to one of the analytes, respectively, such that each combination of chemosensor and analytes results in a different fluorescence output signal, in this example emission color. In a more simple approach, at least the simultaneous presence of the two analytes can be detected if two independent quenching pathways are caused by the two receptor units (Scheme 10, approach B). In this case, only the binding of both analytes prevents the quenching and the molecule lights up, whereas in the presence of only one of the analytes the other quenching pathway still operates. Obviously, both approaches can only be realized when a very delicate balance is provided between the different binding constants and between absorption and emission properties of each distinct state, because the detection event as well as the fluorimetric response have to be highly selective and should not compete or interfere with each other. Accordingly, the situation is getting even more complicated and challenging when more 
than two analytes have to be detected. Notwithstanding, several bi- or multifunctional fluorescent probes have been developed that enable the detection of different analytes; and an extensive upto-date compilation of such probes, with an emphasis on the application as lab-on-a-molecule probes and orthogonal sensing, has been published recently. ${ }^{2}$

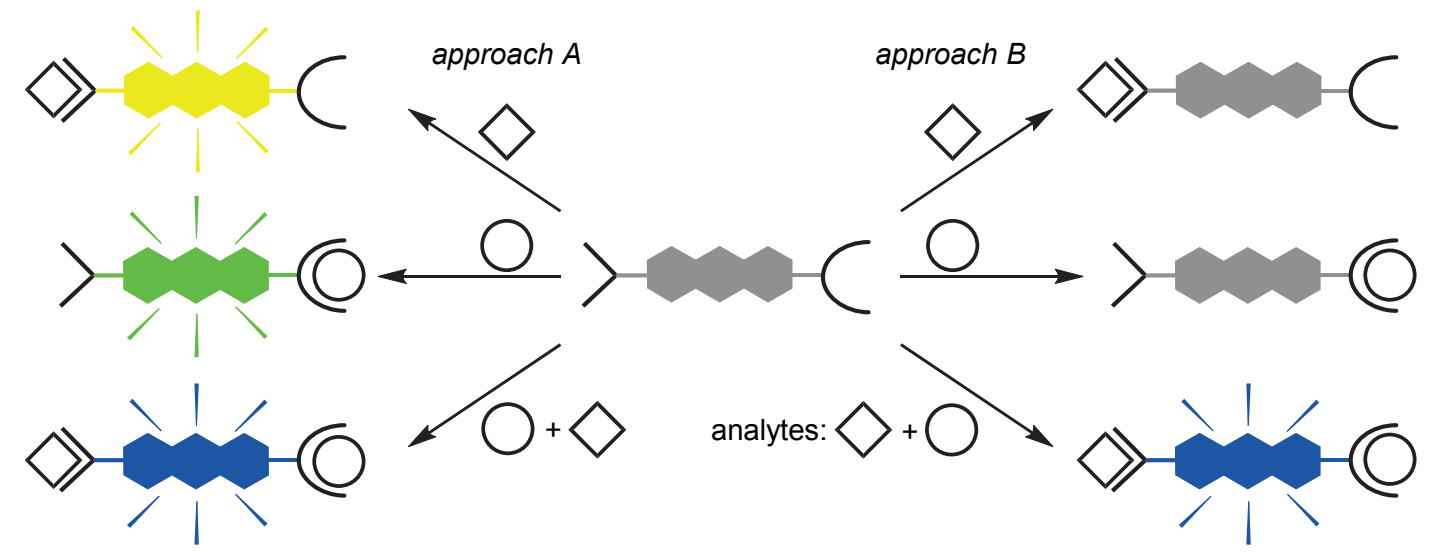

Scheme 10. Simplifying cartoon to demonstrate the principle of optimal multi-color multianalyte sensing.

A survey of multi-analyte fluorescent chemosensors reveals that the majority of multi-analyte probes is designed for the differentiation of analytes from the same general class of compounds, e.g. cations, anions, amino acids. ${ }^{2}$ At the same time, probes that allow the optical detection of different types of analytes are rather rare. ${ }^{134}$ Therefore, we focused our attention on the development of probes that enable the fluorimetric detection of targets from different classes of compounds. As the construction of probes with several different output signals is obviously a difficult and often impossible task (see discussion above), we decided to use a sensing mechanism that indicates the presence of two analytes by a fluorescent light-up effect (Scheme 10 , approach $B$ ). Our general plan of attack rested on observations that neither increasing viscosity of the medium, nor the association with DNA resulted a fluorescence light-up effect in donor-substituted 9-( $N$-arylamino)benzo[ $b]$ quinolizinium derivatives (see $\mathbf{8 b}$ in Scheme 5$).{ }^{95}$ We explained this behavior with a photoinduced electron transfer reaction as additional independent deactivation pathway in the excited state (Scheme 11). This assumption was supported by a linear relationship between donor strength of the substituent and the Hammett substituent constant $\sigma$. In addition, we demonstrated in a key experiment that the two potential deactivation pathways of the excited 9-( $N$-arylamino)benzo $[b]$ quinolizinium can be addressed independently and used for the simultaneous fluorimetric detection of two different analytes or stimuli. Hence, the 4-dimethylamino-substituted derivative $\mathbf{8 c}$ is essentially non-fluorescent in aqueous solution. 


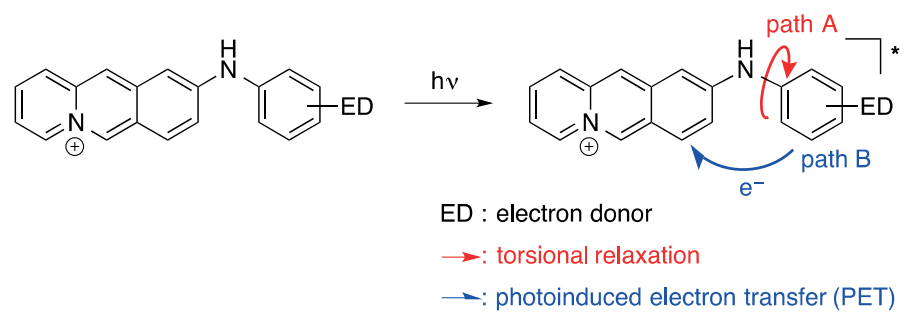

Scheme 11. Deactivation of excited donor-substituted 9 - $(N$-arylamino)benzo[ $b]$ quinolizinium derivatives by torsional relaxation (red) and photoinduced electron transfer (blue).

In contrast to the derivatives $\mathbf{8 c}$ the emission of the amino-substituted probe $\mathbf{8 c}$ does not increase in glycerol solution. Although the torsional relaxation (path A) is suppressed, the excited state is still deactivated by a radiationless PET process (path B). At the same time, the transformation of the dimethylamino group into an electron-accepting ammonium substituent by protonation suppresses the PET reaction in aqueous solution, but it does not lead to a light-up effect at low-viscosity conditions, because in these media the torsional relaxation still takes place. However, when the protonation is performed in viscous glycerol solution, both nonradiative deactivation processes are suppressed in the excited state leading to an intense green fluorescence (Figure 12). These results nicely demonstrated that with an appropriate substitution pattern, the 9-( $N$-arylamino)benzo[b]quinolizinium may be employed for the simultaneous detection of two independent chemical or physical inputs, in this particular case proton concentration and viscosity. In this context, it should be noted that several examples of viscositydependent and $\mathrm{pH}$-sensitive fluorescent probes have been reported, ${ }^{135,136}$ but to the best of our knowledge the detection of both input parameters in one molecule has not been described.
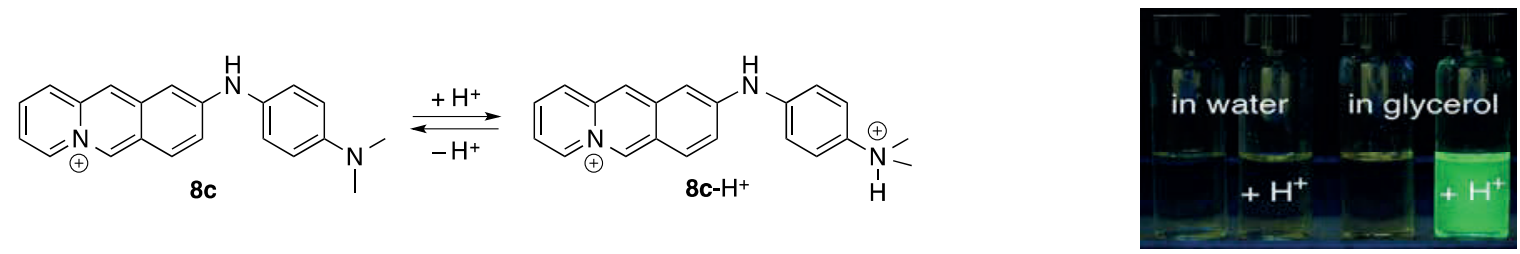

Scheme 12. Emission of 9-[N-(dimethylphenyl)amino]benzo[b]quinolizinium (8c) and its conjugate acid $\mathbf{8 c}-\mathrm{H}^{+}$in water and in glycerol. Adapted with permission from Ref. 95. Copyright 2007 American Chemical Society.

Founded on these observations and our experience with the detection of nucleic acids or cations with 9-aminobenzo[b] quinolizinium derivatives (see above), we proposed that a combination of the different sensing modes should result in a chemosensor that may be used for the simultaneous detection of DNA and metal ions. Accordingly, a 9-( $N$-arylamino)benzo[ $b]$ quinolizinium derivative should serve as a DNA-responsive light-up probe that is connected with a metal ion-sensitive receptor unit to establish a dual-mode chemosensor (Scheme 13). The latter 
should have sufficient electron-donating properties that are reduced upon association with the metal ion. Similar to the mechanism of the $\mathrm{pH}$ - and viscosity-sensitive chemosensor $\mathbf{8 c}$, the intercalation of the intercalator-receptor conjugate into DNA should suppress the torsional deactivation of the excited state, whereas the complexation of the metal ion to the crown ether blocks the PET process; and only if both deactivation pathways are prevented the molecule will light up.
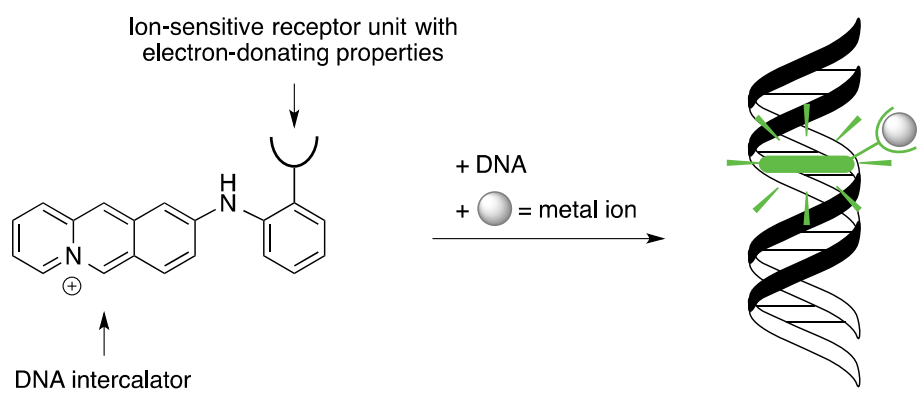

Scheme 13. General structure of a intercalator-receptor conjugate for dual-mode fluorimetric analysis.

In order to test our proposal we investigated a series of $N$-aryl-9aminobenzo $[b]$ quinolizinium crown-ether conjugates that were readily available by nucleophilic aromatic substitution reaction. ${ }^{131}$ It turned out that the derivative $8 \mathbf{i}$ with an azadithiacrown ether in the ortho-position of the phenyl ring fulfills all the requirements of the targetted dual-mode chemosensor. ${ }^{137}$ Firstly, we demonstrated with spectroscopic analyses that this compound forms complexes with $\mathrm{Hg}^{2+}$ ions $\left(K_{\mathrm{b}}=1.0 \times 10^{5} \mathrm{M}^{-1}\right.$ in aqueous buffer $)$ and intercalates into DNA $\left(K_{b}\right.$ $\left.=1.6 \times 10^{5} \mathrm{M}^{-1}\right)$. In addition, the formation of a ternary complex between the ligand, DNA and $\mathrm{Hg}^{2+}$ was confirmed by absorption and CD spectroscopy. In aqueous solution the free ligand has a low fluorescence quantum yield $\left(\Phi_{\mathrm{fl}}<0.001\right)$, because the excited state is deactivated by rotation about the $\mathrm{C}_{\mathrm{Ph}}-\mathrm{N}$ bond (Scheme 8 , path $\mathrm{A}$ ) and by a PET from the aminophenyl unit to the excited benzo[b]quinolizinium (Scheme 8, path B). If only one of these deactivation pathways is suppressed, namely by the complexation of the electron-donating azacrown ether or by the intercalation of the ligand with DNA, the emission is still quenched by the other deactivation process. However, if both pathways are suppressed by simultaneous complexation of $\mathrm{Hg}^{2+}$ and DNA-intercalation, the emission intensity increases. Thus, the chemosensor 14 enables the unambiguous detection of $\mathrm{Hg}^{2+}$ in the close proximity of DNA. To be emphasized is the fact that there is no interfering background signal due to the association of 14 with $\mathrm{Hg}^{2+}$ or DNA alone. 

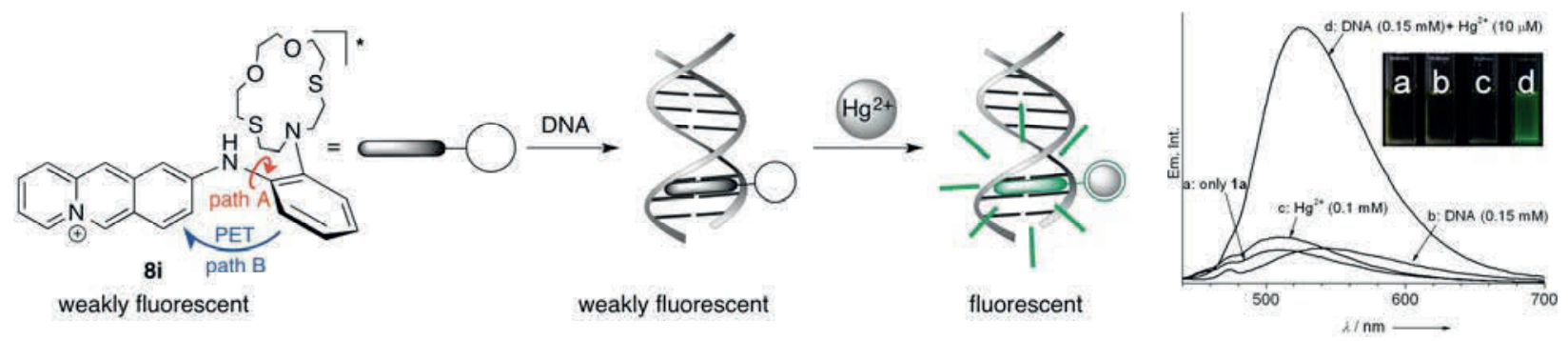

Scheme 14. B: Emission of the cation receptor-intercalator conjugate $8 \mathbf{i}$ in the presence of DNA and $\mathrm{Hg}^{2+}$ ions. Right: Emission spectra of $8 \mathbf{i}(10 \mu \mathrm{M})$ in the presence of ct DNA $(0.15 \mathrm{mM})$, $\mathrm{Hg}^{2+}(0.1 \mathrm{mM})$, or DNA and $\mathrm{Hg}^{2+}(0.15 \mathrm{mM}$ and $10 \mu \mathrm{M}$ resp.). Reproduced from Ref. 137 with permission from the Royal Society of Chemistry.

\subsection{Summary}

We have corroborated that the combination of the emission properties of the water-soluble 9aminobenzo[b]quinolizinium with functional groups, that interact selectively with a target analyte, represents a promising and versatile tool for the development of chemosensors for the selective fluorimetric detection of biologically relevant analytes. Specifically, several approaches to accomplish selective light-up effects and ratiometric detection of analytes were realized, and the mechanisms and chemosensor-analyte interactions were assessed by detailed photochemical and photophysical studies. In a consequent development, these principles were applied for the design of novel multi-color and dual-mode chemosensors.

\section{Acknowledgements}

This work was generously financed by the Deutsche Forschungsgemeinschaft (DFG; grant no. IH 24/2-2; IH 24/2-3; IH 24/4-1; IH 24/2-4; IH 24/6-1), the Deutscher Akademische Austauschdienst (DAAD), Fonds der Chemischen Industrie, and the University of Siegen. With sincere gratitude HI thanks his coworkers - past and present - from the "chemosensor group", namely - in alphabetic order - Dr. Katja Benner, Dr. Anna Bergen, Dr. Katja Faulhaber, Dr. Anton Granzhan, Haixing Li, Jennifer Hermann, Dr. Christian Mohrschladt, Dr. Daniela Otto, Dr. Thomas Paululat, Dr. Maoqun Tian, Sandra Uebach, Katy Schäfer, Dr. Laura Thomas, Dr. Michael Waidelich, Shi Te Ye, Sharon Wells (RISE, DAAD), Michael Towler (Huntsville TX, DAAD) for their dedicated work; as well as his cooperation partners Prof. Dr. Cornelia Bohne, University of Victoria, B.C., Dr. Giampietro Viola, University of Padova, Italy, and Prof. Dr. Rick C. White, Sam Houson State University, Huntsville, TX, for the fruitful and inspiring discussions. 


\section{References}

1. Desvergne, J. P.; Czarnik, A. W.. Chemosensors of Ion and Molecule Recognition, Kluwer Academic: London, 1997. The term chemosensor is often used to clearly distinguish fluorescent probes from sensors, i.e. integral sensing devices.

2. Chen, K.; Shu, Q.; Schmittel, M. Chem. Soc. Rev. 2015, 44, 136. http://dx.doi.org/10.1039/C4CS00263F

3. Daly, B.; Ling, J.; de Silva, A. P. Chem. Soc. Rev. 2015, 44, 4203. http://dx.doi.org/10.1039/C4CS00334A

4. Yang, Z.; Cao, J.; He, Y.; Yang, J. H.; Kim, T.; Peng, X.; Kim, J. S. Chem. Soc. Rev. 2014, 43, 4563.

http://dx.doi.org/10.1039/c4cs00051j

5. You, Y.; Nam, W. Chem. Sci. 2014, 5, 4123.

http://dx.doi.org/10.1039/C4SC01637H

6. Yao, J.; Yang, M.; Duan, Y. Chem. Rev. 2014, 114, 6130.

http://dx.doi.org/10.1021/cr200359p

7. Carter, K. P.; Young, A. M.; Palmer, A. E. Chem. Rev. 2014, 114, 4564. http://dx.doi.org/10.1021/cr400546e

8. Pal, S.; Chatterjee, N.; Bharadwaj, P. K. RSC Adv. 2014, 4, 26585. http://dx.doi.org/10.1039/c4ra02054e

9. Panchenko, P. A.; Fedorova, O. A.; Fedorov, Y. V. Russ. Chem. Rev. 2014, 83, 155. http://dx.doi.org/10.1070/RC2014v083n02ABEH004380

10. Li, X.; Gao, X.; Shi, W.; Ma, H.; Chem. Rev. 2014, 114, 590. http://dx.doi.org/10.1021/cr300508p

11. Diehl, K. L.; Anslyn, E. V. Chem. Soc. Rev. 2013, 42, 8596. http://dx.doi.org/10.1039/c3cs60136f

12. Yang, Y.; Zhao, Q.; Feng, W.; Li, F. Chem. Rev. 2013, 113, 192. http://dx.doi.org/10.1021/cr2004103

13. Wang, B.; Anslyn, E. Chemosensors; Wiley: New Jersey, 2011. http://dx.doi.org/10.1002/9781118019580

14. Lakowicz, R. Principles of Fluorescence Spectroscopy; Plenum Publishing: New York, 2010; rev. 3rd ed.

15. Wang, S.; Li, N.; Pan, W.; Tang, B. Trends Anal. Chem. 2012, 39, 3. http://dx.doi.org/10.1016/j.trac.2012.07.010

16. Demchenko, A. P. Introduction to Fluorescence Sensing; Springer: Berlin, 2009. http://dx.doi.org/10.1007/978-1-4020-9003-5

17. de Silva, A. P.; Uchiyama, S. Top. Curr. Chem. 2011, 300, 1. http://dx.doi.org/10.1007/128 201096

18. Wysocki, L. M.; Lavis, L. D. Curr. Opin. Chem. Biol. 2011, 15, 752. http://dx.doi.org/10.1016/j.cbpa.2011.10.013 
19. Valeur, B. Molecular Fluorescence: Principles and Applications; Wiley-VCH: Weinheim, 2002.

20. Lee, M. H.; Kim, J. S.; Sessler, J. L. Chem. Soc. Rev. 2015, 44, 4185. http://dx.doi.org/10.1039/C4CS00280F

21. Li, X.; Gao, X.; Shi, W.; Ma, H. Chem. Rev. 2014, 114, 590. http://dx.doi.org/10.1021/cr300508p

22. Yoshizawa, M.; Klosterman, J. K. Chem. Soc. Rev. 2014, 43, 1885; and references cited therein.

http://dx.doi.org/10.1039/C3CS60315F

23. Lehnherr D.; Tykwinski, R. R. Aust. J. Chem. 2011, 64, 919; and references cited therein. http://dx.doi.org/10.1071/CH11169

24. de Silva, A. P.; Vance, T. P.; West, M. E. S.; Wright, G. D. Org. Biomol. Chem. 2008, 6, 2468; and references cited therein

http://dx.doi.org/10.1039/b802963f

25. Becker, H.-D. Chem. Rev. 1993, 93, 145; and references cited therein http://dx.doi.org/10.1021/cr00017a008

26. Huston, M.; Haider, K.; Czarnik, A. W. J. Am. Chem. Soc. 1988, 110, 4460. http://dx.doi.org/10.1021/ja00221a083

27. Butts, C. A.; Xi, J. Brannigan, G.; Saad, A. A.; Venkatachaland, S. P.; Pearce, R. A.; Klein, M. L.; Eckenhoff, R. G.; Dmochowski, I. J. Proc. Natl. Acad. Sci. 2009, 106, 6501. http://dx.doi.org/10.1073/pnas.0810590106

28. Witulski, B.; Weber, M.; Bergsträsser, U.; Desvergne, J.-P.; Bassani, D. M.; BouasLaurent, H. Org. Lett. 2001, 3, 1467.

http://dx.doi.org/10.1021/o1015778j

29. Natarajan, P.; Schmittel, M. J. Org. Chem. 2012, 77, 8669.

http://dx.doi.org/10.1021/jo301616t

30. Ghosh, K.; Ranjan Sarkar, A.; Ghorai, A.; Ghosh, U. New. J. Chem. 2012, 36, 1231. http://dx.doi.org/10.1039/c2nj21024j

31. Huang, Y. Zhang, Y.; Zhang, J.; Zhang, D.-W.; Lu, Q.-S.; Liu, J.-L.; Chen, S.-Y.; Lin, H.H.; Yu, X.-Q. Org. Biomol. Chem. 2009, 7, 2278.

http://dx.doi.org/10.1039/c2nj21024j

32. Duff, M. R.; Tan, W. B.; Bhambhani, A.; Perrin, B. S.; Thota, J.; Rodger A.; Kumar, C. V. J. Phys. Chem. B 2006, 110, 20693. http://dx.doi.org/10.1021/jp063997m

33. Kumar, C. V.; Punzalan, E. H. A.; Tan, W. B. Tetrahedron 2000, 56, 7027. http://dx.doi.org/10.1016/S0040-4020(00)00526-3

34. Kumar, C. V.; Asuncion, E. H. J. Am. Chem. Soc. 1993, 115, 8547. http://dx.doi.org/10.1021/ja00072a004

35. Bradsher, C. K. In Comprehensive Heterocyclic Chemistry; Katritzky, A. R.; Rees, C. W. Eds.; Pergamon: Oxford, 1984, Vol. 2; p 525. 
http://dx.doi.org/10.1016/B978-008096519-2.00032-1

36. Arai, S.; Hida, M. Adv. Heterocyclic Chem. 1992, 55, 261.

http://dx.doi.org/10.1016/S0065-2725(08)60223-8

37. Vaquero, J. J.; Alvarez-Builla, J. In Modern Heterocyclic Chemistry; Alvarez-Builla, J.; Vaquero, J. J.; Barluenga, J. Eds.; Wiley-VCH: Weinheim, 2011, p 1989. http://dx.doi.org/10.1002/9783527637737.ch22

38. Ihmels, H. In Science of Synthesis, Volume 15: Six-Membered Hetarenes with One Nitrogen or Phosphorus Atom; Thomas, J. Ed.; Georg Thieme Verlag: Stuttgart, 2011, p 75.

39. Ihmels, H. In Science of Synthesis, Volume 15: Six-Membered Hetarenes with One Nitrogen or Phosphorus Atom, Black, D. Ed.; Georg Thieme Verlag: Stuttgart, 2004, 907.

40. Bradsher, C. K.; Beavers, L. E. J. Am. Chem. Soc. 1955, 77, 4812. http://dx.doi.org/10.1021/ja01623a036

41. Bradsher, C. K.; Solomons, T. W. G.; Vaughan, F. R. J. Org. Chem. 1960, 25, 757. http://dx.doi.org/10.1021/jo01075a021

42. Bradsher. C. K.; Parham, J. C. J. Org. Chem. 1963, 28, 83. http://dx.doi.org/10.1021/jo01036a018

43. Krapcho, A. P.; Cadamuro, S. A.; Macnee, L. ARKIVOC 2007, ix, 28; and references cited therein.

44. Potikha, L. M.; Sypchenko, V. V.; Kovtunenko, V. A. Chem. Heterocyclic Comp. 2013, 49, 294.

http://dx.doi.org/10.1007/s10593-013-1246-9

45. Earley, W. G.; Kumar, V.; Mallamo, J. P.; Subramanyam, C.; Dority, J. A. Jr; Miller, M. S.; DeHaven-Hudkins, D. L.; Aimone, L. D.; Kelly, M. D.; Ault, B. J. Med. Chem. 1995, 38,3586 .

http://dx.doi.org/10.1021/jm00018a018

46. Earley, W. G.; Dority Jr., J. A.; Kumar, V.; Malamo, J. P. Heterocycles 1995, 41, 309. http://dx.doi.org/10.3987/COM-94-6936

47. Turner, J. D.; Bradsher, C. K. J. Org. Chem. 1967, 32, 1169. http://dx.doi.org/10.1021/jo01279a070

48. Bradsher, C. K.; Braun, L. L.; Turner, J. D.; Walker, G. L. J. Org. Chem. 1974, 39, 1157. http://dx.doi.org/10.1021/jo00922a032

49. Bradsher, C. K.; Turner, J. D. J. Org. Chem. 1966, 31, 565. http://dx.doi.org/10.1021/jo01340a052

50. Granzhan, A.; Ihmels, H. ARKIVOC 2007, viii, 136.

51. Deiseroth, H.-J.; Granzhan, A.; Ihmels, H.; Schlosser, M.; Tian, M.; Org. Lett. 2008, 5, 757.

http://dx.doi.org/10.1021/o1702792r

52. Tian, M.; Ihmels, H. Synthesis 2009, 4226. 
53. Caneque, T.; Cuadro, A. M.; Alvarez-Builla, J.; Vaquero, J. J. Tetrahedron Lett. 2009, 50, 1419. http://dx.doi.org/10.1016/j.tetlet.2009.01.040

54. García-Cuadrado, D.; Cuadro, A. M.; Barchín, B. M.; Nuñez, A.; Cañeque, T.; AlvarezBuilla, J.; Vaquero, J. J. J. Org. Chem. 2006, 71, 7989.

http://dx.doi.org/10.1021/jo060634+

55. García, D.; Cuadro, A. M.; Alvarez-Builla, J.; Vaquero, J. J. Org. Lett. 2004, 6, 4175. http://dx.doi.org/10.1021/o1048368e

56. Jones, G. Adv. Heterocyclic Chem. 1982, 31, 1. http://dx.doi.org/10.1016/S0065-2725(08)60395-5

57. Saraf, S.-U.-D. Heterocycles 1981, 16, 803. http://dx.doi.org/10.3987/R-1981-05-0803

58. Saraf, S.-U.-D. Heterocycles 1980, 14, 2047. http://dx.doi.org/10.3987/R-1980-12-2047

59. Miyasera, T.; Tachikawa, R. Tetrahedron 1969, 25, 5189. http://dx.doi.org/10.1016/0040-4020(69)80039-6

60. Brown, L. R.; Bradsher, C. K. J. Org. Chem. 1966, 66, 1296.

61. Bradsher, C. K.; Sherer, J. P. J. Org. Chem. 1967, 32, 733. http://dx.doi.org/10.1021/jo01278a051

62. Bradsher, C. K.; Jones, J. H. J. Am. Chem. Soc. 1959, 81, 1938. http://dx.doi.org/10.1021/ja01517a039

63. Bouas-Laurent, H.; Castellan, A.; Desvergne, J.-P.; Lapouyade, R. Chem. Soc. Rev. 2000, $29,43$.

http://dx.doi.org/10.1039/a801821i

64. Bailey, D. E.; Williams, V. E.; J. Org. Chem. 2006, 71, 5778. http://dx.doi.org/10.1021/jo060838q

65. Grimme, S.; Diedrich, C.; Korth, D. Angew. Chem. 2006, 118, 641. http://dx.doi.org/10.1002/ange.200502440

66. Islangulov, R.; Casterllano, F. N. Angew. Chem. 2006, 118, 6103. http://dx.doi.org/10.1002/ange.200601615

67. Ihmels, H.; Leusser, D.; Pfeiffer, M.; Stalke, D. Tetrahedron 2000, 56, 6867. http://dx.doi.org/10.1016/S0040-4020(00)00508-1

68. Ihmels, H.; Luo, J. J. Photochem. Photobiol. A: Chem. 2008, 200, 3. http://dx.doi.org/10.1016/j.jphotochem.2008.04.008

69. Bradsher, C. K.; Beavers, L. E.; Jones, J. H. J. Org. Chem. 1957, 129, 1740. http://dx.doi.org/10.1021/jo01363a640

70. Lehnberger, C.; Scheller, D.; Wolff, T. Heterocycles 1997, 45, 2033. http://dx.doi.org/10.3987/COM-97-7891

71. Ihmels, H. Tetrahedron Lett. 1998, 39, 8641. http://dx.doi.org/10.1016/S0040-4039(98)02040-1 
72. Stratford, S. A.; Arhangelskis, M.; Bucar, D.-K.; Jones, W. CrystEngComm 2014, 16, 10830.

http://dx.doi.org/10.1039/C4CE01622J

73. Ihmels, H.; Leusser, D. Pfeiffer, M. Stalke, D. Mol. Cryst. Liq. Cryst. 2001, 356, 433. http://dx.doi.org/10.1080/10587250108023721

74. Ihmels, H.; Leusser, D.; Pfeiffer, M.; Stalke, D. J. Org. Chem. 1999, 64, 5715. http://dx.doi.org/10.1021/jo990465b

75. Wang, W.-N.; Jones, W. Mol. Cryst. Liq. Cryst. 1994, 242, 227. http://dx.doi.org/10.1080/10587259408037755

76. Wang, W.-N.; Jones, W. Tetrahedron 1987, 43, 1273. http://dx.doi.org/10.1016/S0040-4020(01)90248-0

77. Wirp, C.; Bendig, J.; Brauer, H.-D. Ber. Bunsenges. Phys. Chem. 1997, 101, 961. http://dx.doi.org/10.1002/bbpc.19971010611

78. Helm, S.; Bendig, J.; Kreysig, D. J. Prakt. Chem. 1988, 330, 947. http://dx.doi.org/10.1002/prac.19883300613

79. J. Bendig, S. Helm, D. Kreysig, J. Prakt. Chem. 1982, 330, 978. http://dx.doi.org/10.1002/prac.19823240617

80. Bendig, J.; Wagner, J.; Buchwitz, W.; Kreysig, D. Ber. Bunsenges. Phys. Chem. 1981, 85, 437.

http://dx.doi.org/10.1002/bbpc.19810850519

81. Bendig, J.; Helm, S.; Kreysig, D. J. Prakt. Chem. 1977, 319, 807. http://dx.doi.org/10.1002/prac.19773190517

82. Saraf, S.-U.-D. Heterocycles 1981, 16, 987. http://dx.doi.org/10.3987/R-1981-06-0987

83. Galasso, V.; De Alti, G. Gazz. Chim. Ital. 1970, 100, 421.

84. Zollinger, H. Color Chemistry, 3rd ed.; VCH: Weinheim, Germany, 2003.

85. Choudhury, S. D.; Muralidharan, S.; Pal, H. Phys. Chem. Chem. Phys. 2014, 16, 11509, and references cited therein. http://dx.doi.org/10.1039/c4cp00865k

86. Lu, Z.; Lord, S. J.; Wang, H.; Moerner, W. E.; Twieg, R. J. J. Org. Chem. 2006, 71, 9651. http://dx.doi.org/10.1021/jo0616660

87. Ihmels, H.; Meiswinkel, A.; Mohrschladt, C. J.; Otto, D.; Waidelich, M.; Towler, M.; White, R.; Albrecht, M.; Schnurpfeil, A. J. Org. Chem. 2005, 70, 3929. http://dx.doi.org/10.1021/jo047841z

88. Ihmels, H. Eur. J. Org. Chem. 1999, 1595. http://dx.doi.org/10.1002/(SICI)1099-0690(199907)1999:7<1595::AIDEJOC1595>3.0.CO;2- D

89. Sun, S.; Desper, J. Tetrahedron 1998, 54, 411. http://dx.doi.org/10.1016/S0040-4020(97)10300-3 
90. Gundermann, K. D.; Klockenbring, G.; Roker, C.; Brinkmeyer, H. Liebigs Ann. Chem. 1976, 1873.

91. Bradsher, C. K.; Jones, H. J. J. Am. Chem. Soc. 1957, 79, 6033. http://dx.doi.org/10.1021/ja01579a050

92. Ihmels, H.; Engels, B.; Faulhaber, K.; Lennartz, C. Chem. Eur. J. 2000, 6, 2854. http://dx.doi.org/10.1002/1521-3765(20000804)6:15<2854::AID-CHEM2854>3.0.CO;2-5

93. Faulhaber, K.; Granzhan, A.; Ihmels, H.; Otto, D.; Thomas, L.; Wells, S. Photochem. Photobiol. Sci. 2011, 10, 1535. http://dx.doi.org/10.1039/c1pp05106g

94. Faulhaber, K., Disseration, Universität Würzburg, 2003. Unfortunately, a picture of this series of compounds (2a-h) in water is not available.

95. Granzhan, A.; Ihmels, H.; Viola, G. J. Am. Chem. Soc. 2007, 129, 1254. http://dx.doi.org/10.1021/ja0668872

96. Xie, Y.; Tam, V. K.; Tor, Y. In The chemical biology of nucleic acids, Mayer, G. Ed.; John Wiley \& Sons: Chichester: 2010, p. 115. http://dx.doi.org/10.1002/9780470664001.ch6

97. Ihmels, H.; Thomas, L. In Materials Science of DNA Chemistry; Jin, J.-I. Ed.; CRC Press: Boca Raton, 2011, p 49. http://dx.doi.org/10.1201/b11290-4

98. Hannon, M. J. Chem. Soc. Rev. 2007, 36, 280. http://dx.doi.org/10.1039/B606046N

99. Haq, I. In Nucleic acids in chemistry and biology; Blackburn, G. M.; Gait, M. J.; Loakes, D.; Williams, D. M. Eds.; Royal Society of Chemistry: Cambridge, 2006, p 341.

100. Jäger, K.; Bats, J. W.; Ihmels, H.; Granzhan, A.; Uebach, S.; Patrick, B. O. Chem. Eur. J. 2012, 18, 10903. http://dx.doi.org/10.1002/chem.201103019

101. Granzhan, A.; Ihmels H.; Jäger, K. Chem. Comm. 2009, 1249.

102. Basili, S.; Bergen, A.; Dall'Acqua, F.; Faccio, A.; Granzhan, A.; Ihmels, H.; Moro S.; Viola, G. Biochemistry 2007, 46, 12721.

http://dx.doi.org/10.1021/bi701518v

103. Ihmels, H.; Otto, D.; Faccio, A.; Viola, G. J. Org. Chem. 2006, 71, 8401. http://dx.doi.org/10.1021/jo0612271

104. Granzhan, A.; Ihmels, H. ChemBioChem 2006, 7, 1031. http://dx.doi.org/10.1002/cbic.200600065

105. Benner, K.; Ihmels, H.; Kölsch, S.; Pithan, P. M. Org. Biomol. Chem. 2014, 12, 1725. http://dx.doi.org/10.1039/C3OB42140F

106. Benner, K.; Bergen, A.; Ihmels, H.; Pithan, P. M. Chem. Eur. J. 2014, 20, 9883. http://dx.doi.org/10.1002/chem.201403622

107. Bohne, C.; Faulhaber, K.; Giese, B.; Häfner, A.; Hofmann, A.; Ihmels, H.; Köhler, A.-K.; Perä, S.; Schneider, F.; Sheepwash, M. A. L. J. Am. Chem. Soc. 2005, 126, 76. 
http://dx.doi.org/10.1021/ja046189m

108. Kosower, E. M. Acc. Chem. Res. 1982, 15, 259.

http://dx.doi.org/10.1021/ar00080a005

109. Faulhaber, K.; Granzhan, A.; Ihmels, H.; Viola, G. Pure Appl. Chem. 2006, 78, 2325. http://dx.doi.org/10.1351/pac200678122325

110. Granzhan, A.; Ihmels, H. Org. Lett. 2005, 7, 5119. http://dx.doi.org/10.1021/o1051624i

111. Cosa, G.; Focsaneanu, K. S.; McLean, J. R. N.; McNamee, J. P.; Scaiano. J. S. Photochem. Photobiol. 2001, 73, 585.

http://dx.doi.org/10.1562/0031-8655(2001)073<0585:PPOFDD>2.0.CO;2

112. Bortolozzi, R.; Ihmels, H.; Thomas, L.; Tian, M.; Viola, G. Chem. Eur. J. 2013, 19, 8736. http://dx.doi.org/10.1002/chem.201301164

113. Grabowski, Z. R.; Rotkiewicz, K. Chem. Rev. 2003, 103, 3899. http://dx.doi.org/10.1021/cr9407451

114. Singha, S.; Kim, D.; Seo, H.; Cho, S. W.; Ahn, K. H. Chem. Soc. Rev. 2015, 44, 4367. http://dx.doi.org/10.1039/C4CS00328D

115. Cotruvo, J. A. Jr.; Aron, A. T.; Ramos-Torres, K. M.; Chang, C. J. Chem. Soc. Rev. 2015, $44,4400$.

http://dx.doi.org/10.1039/C4CS00346B

116. Hamilton, G. R. C.; Sahoo, S. K.; Kamila, S.; Singh, N.; Kaur, N; Hyland, B. W.; Callan, J. F. Chem. Soc. Rev. 2015, 44, 4415. http://dx.doi.org/10.1039/C4CS00365A

117. Kim, H. N.; Ren, W. X.; Kim, J. S.; Yoon, J. Chem. Soc. Rev. 2012, 41, 3210. http://dx.doi.org/10.1039/C1CS15245A

118. Quang, D. T.; Kim, J. S. Chem. Rev. 2010, 110, 6280.

http://dx.doi.org/10.1021/cr100154p

119. Tian, M.; Ihmels, H.; Brötz, E. Dalton Trans., 2010, 39, 8195. http://dx.doi.org/10.1021/cr100154p

120. Carol, P.; Sreejith S., Ajayaghosh, A. Chem. Asian J. 2007, 2, 338. http://dx.doi.org/10.1002/asia.200600370

121. Irving H. M. N. H.; Williams, R. J. P. J. Chem. Soc. 1953, 3192. http://dx.doi.org/10.1039/jr9530003192

122. Domaille, D. W.; Zeng L.; Chang, C. J. J. Am. Chem. Soc. 2010, 133, 1194. http://dx.doi.org/10.1021/ja907778b

123. Yin, B.-C.; Ye, B.-C.; Tan, W.; Wang H.; Xie, C.-C. J. Am. Chem. Soc. 2009, 131, 14624. http://dx.doi.org/10.1021/ja9062426

124. Liu J.; Lu, Y. J. Am. Chem. Soc. 2007, 129, 9838 http://dx.doi.org/10.1021/ja0717358

125. Kovacs, J.; Rödler T.; Mokhir, A. Angew. Chem. Int. Ed. 2006, 45, 7815. $\underline{\text { http://dx.doi.org/10.1002/anie.200603391 }}$ 
126. Singhal, N. K.; Ramanujam, B.; Mariappanadar V.; Rao, C. P. Org. Lett. 2006, 8, 3525. http://dx.doi.org/10.1021/o1061274f

127. Li, Y.; Yang, C. M. Chem. Commun. 2003, 2884. http://dx.doi.org/10.1039/b310543a

128. Jagt, R. C. B.; Kheibari, M. S.; Nitz, M., Dyes Pigm. 2009, 81, 161. http://dx.doi.org/10.1016/j.dyepig.2008.10.003

129. Späth, A.; König, B. Beilstein J. Org. Chem. 2010, 6, 1. http://dx.doi.org/10.3762/bjoc.6.32

130. Tian, M.; Ihmels, H. Chem. Commun. 2009, 3175. http://dx.doi.org/10.1039/b821830g

131. Tian, M.; Ihmels, H. Eur. J. Org. Chem. 2011, 4145. http://dx.doi.org/10.1002/ejoc.201100329

132. Tian, M.; Ihmels, H.; Ye, S. Org. Biomol. Chem. 2012, 10 , 3010. http://dx.doi.org/10.1039/c2ob06948b

133. Tusa, J. K.; He, H. J. Mater. Chem. 2005, 15, 2640. http://dx.doi.org/10.1039/b503172a

134. He X.; Yam, V. W.-W. Org. Lett. 2011, 13, 2172. http://dx.doi.org/10.1021/ol200277n

135. Kuimova, M. K. Phys. Chem. Chem. Phys. 2012, 14, 12671. http://dx.doi.org/10.1039/c2cp41674c

136. Haidekker, M. A.; Theodorakis, E. A. Org. Biomol. Chem. 2007, 5, 1669. http://dx.doi.org/10.1039/b618415d

137. Tian, M.; Ihmels, H.; Benner, K. Chem. Commun. 2010, 46, 5719. http://dx.doi.org/10.1039/c002727h

\section{Authors' Biographies}

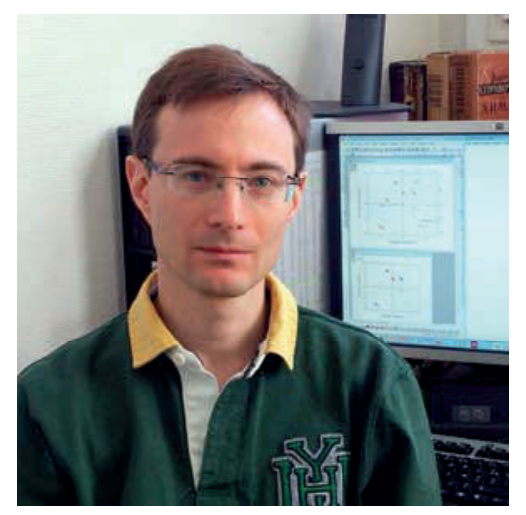

Anton Granzhan graduated from the National Technical University in Kiev (Ukraine) in 2002 and performed his Ph.D. studies in organic chemistry under the supervision of Prof. Heiko Ihmels at the University of Siegen (Germany). After post-doctoral stays at Collège de France 
(Paris), Institut Curie (Orsay, France) and École Polytechnique Fédérale de Lausanne (Switzerland), in 2010 he was appointed CNRS Research Scientist at Institut Curie (Orsay, France). His research interests include development of ligands and fluorescent probes for recognition of unusual DNA structures as well as applications of supramolecular chemistry to biological targets.

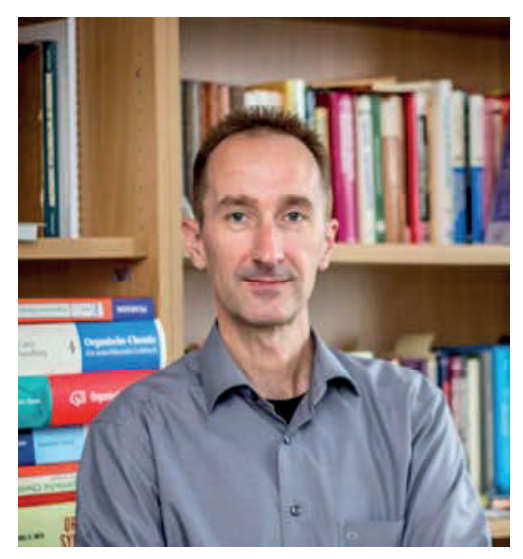

Heiko Ihmels received both his Diploma (1992) and his Ph.D. (1995, with Dr. Johannes Belzner and Prof. Armin de Meijere) from the University of Göttingen, Germany. He enjoyed 15 months as a postdoctoral fellow with Prof. John R. Scheffer at the University of British Columbia, Vancouver, Canada. He joined the University of Würzburg, Germany, in 1997, where he obtained his habilitation in Organic Chemistry in 2002. Since 2003 he occupies a Chair of Organic Chemistry at the University of Siegen, Germany. His research interests lie in the field of bioorganic chemistry and organic photochemistry; in particular in DNA-binding and DNAphotodamaging properties of cationic hetarenes; in solid-state photochemistry, and in the development of fluorescent chemosensors.

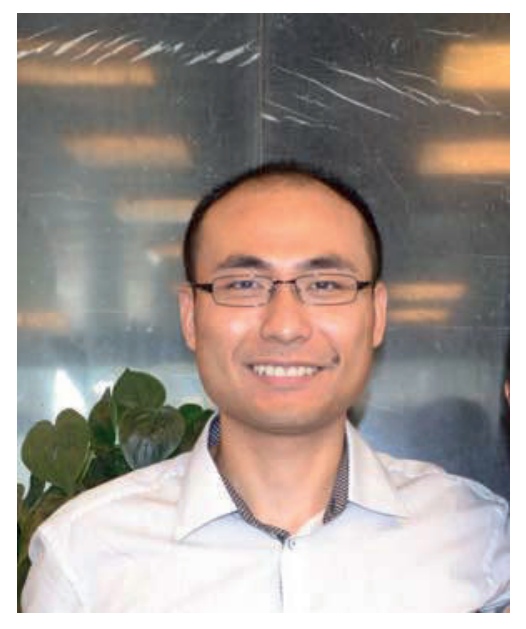

Maoqun Tian was born in China in 1982. He completed his undergraduate education from Shanghai Jiao Tong University in 2005, at which point he moved to Germany, and obtained his M.Sc. (2007) and Ph.D. (2010) under the supervision of Prof. Dr. Heiko Ihmels at the University 
of Siegen. He then joined the Neuroallianz Consortium at PharmaCenter Bonn as a medicinal chemist until 2013. He is currently a postdoctoral fellow in the research group of Prof. Phil S. Baran at The Scripps Research Institute in the USA pursuing the total synthesis of marine alkaloids. 